\title{
Dynamic response of microglia/ macrophage polarization following demyelination in mice
}

Tianci Chu', Yi Ping Zhang ${ }^{2}$, Zhisen Tian ${ }^{1,3}$, Chuyuan Ye ${ }^{1,4}$, Mingming Zhu ${ }^{5}$, Lisa B. E. Shields ${ }^{2}$, Maiying Kong ${ }^{6}$, Gregory N. Barnes ${ }^{1,7,8}$, Christopher B. Shields ${ }^{2,9^{*}}$ and Jun Cai ${ }^{1,8^{*}}$

\begin{abstract}
Background: The glial response in multiple sclerosis (MS), especially for recruitment and differentiation of oligodendrocyte progenitor cells (OPCS), predicts the success of remyelination of MS plaques and return of function. As a central player in neuroinflammation, activation and polarization of microglia/macrophages (M/M) that modulate the inflammatory niche and cytokine components in demyelination lesions may impact the OPC response and progression of demyelination and remyelination. However, the dynamic behaviors of M/M and OPCS during demyelination and spontaneous remyelination are poorly understood, and the complex role of neuroinflammation in the demyelination-remyelination process is not well known. In this study, we utilized two focal demyelination models with different dynamic patterns of $M / M$ to investigate the correlation between $M / M$ polarization and the demyelination-remyelination process.
\end{abstract}

Methods: The temporal and spatial features of M/M activation/polarization and OPC response in two focal demyelination models induced by lysolecithin (LPC) and lipopolysaccharide (LPS) were examined in mice. Detailed discrimination of morphology, sensorimotor function, diffusion tensor imaging (DTI), inflammation-relevant cytokines, and glial responses between these two models were analyzed at different phases.

Results: The results show that LPC and LPS induced distinctive temporal and spatial lesion patterns. LPS produced diffuse demyelination lesions, with a delayed peak of demyelination and functional decline compared to LPC. Oligodendrocytes, astrocytes, and M/M were scattered throughout the LPS-induced demyelination lesions but were distributed in a layer-like pattern throughout the LPC-induced lesion. The specific M/M polarization was tightly correlated to the lesion pattern associated with balance beam function.

Conclusions: This study elaborated on the spatial and temporal features of neuroinflammation mediators and glial response during the demyelination-remyelination processes in two focal demyelination models. Specific M/M polarization is highly correlated to the demyelination-remyelination process probably via modulations of the inflammatory niche, cytokine components, and OPC response. These findings not only provide a basis for understanding the complex and dynamic glial phenotypes and behaviors but also reveal potential targets to promote/inhibit certain M/M phenotypes at the appropriate time for efficient remyelination.

Keywords: Multiple sclerosis, Focal demyelination model, Oligodendrocyte/oligodendrocyte progenitor cells, Microglia/macrophage, Neuroinflammation, Sensorimotor function, Diffusion tensor imaging

\footnotetext{
* Correspondence: cbshields1@gmail.com; j0cai002@louisville.edu

${ }^{2}$ Norton Neuroscience Institute, Norton Healthcare, 210 East Gray Street, Suite 1102, Louisville, KY 40202, USA

'Department of Pediatrics, Pediatric Research Institute, University of Louisville School of Medicine, Donald Baxter Building, Suite 321B, 570 S. Preston Street, Louisville, KY 40202, USA

Full list of author information is available at the end of the article
}

(C) The Author(s). 2019 Open Access This article is distributed under the terms of the Creative Commons Attribution 4.0 International License (http://creativecommons.org/licenses/by/4.0/), which permits unrestricted use, distribution, and reproduction in any medium, provided you give appropriate credit to the original author(s) and the source, provide a link to the Creative Commons license, and indicate if changes were made. The Creative Commons Public Domain Dedication waiver (http://creativecommons.org/publicdomain/zero/1.0/) applies to the data made available in this article, unless otherwise stated. 


\section{Background}

Remyelination is an endogenous regenerative process of damaged myelin sheaths in the adult central nervous system (CNS) that may restore saltatory conduction, metabolic transport, and trophic support [1-3]. Remyelination naturally occurs in multiple sclerosis (MS). However, it is often inadequate and results in progressive neurodegeneration that leads to chronic disabilities seen clinically [4-8]. This inadequate degree of remyelination is speculated to be related to the reduced recruitment of newly generated oligodendrocyte progenitor cells (OPCs) and the arrested differentiation of OPCs into mature oligodendrocytes (OLs) $[1,5,9,10]$. As there is no efficient therapy to promote remyelination in MS, the underlying mechanisms of $\mathrm{OPC} / \mathrm{OL}$ activity into the relevant cellular and molecular niches require further investigation to elucidate the process of demyelination-remyelination to create novel specific therapies.

Inflammatory responses within the CNS (neuroinflammation) is a major feature of MS [11]. The specific pathological, biochemical, and neurobehavioral consequences are related to the stimulus/injury type, microenvironment, and time-course [12]. As part of the immune system, microglia/macrophages $(\mathrm{M} / \mathrm{M})$ play a central role in neuroinflammation by antigen presentation, phagocytosis of apoptotic cells and cellular debris, as well as by the production of cytokines, chemokines, reactive oxygen species, secondary messengers, and growth/neurotrophic factors [12-14]. As a result of their role in the inflammatory response, $\mathrm{M} / \mathrm{M}$ is implicated in the progression and alleviation of demyelination lesions [14-19]. This response is based not only on the presence of $\mathrm{M} / \mathrm{M}$ but also on the phenotypic balance/switch of M/M that affects the severity of demyelination as well as the timing and efficiency of remyelination, presumably by alternating the behavior of OPCs $[14-17,20,21]$. The "classically activated" M1phenotype is considered to be related to increased antigen presentation and production of pro-inflammatory cytokines and toxic molecules $[16,22]$, while the "alternatively activated" M2-phenotype is associated with remyelination by promoting OPC differentiation through the generated growth factors [16]. However, the temporal detail of M/M activation, polarization, and localization pattern of different $\mathrm{M} / \mathrm{M}$ phenotypes, along with the response of OPC/ $\mathrm{OL}$ at the same time-points, are poorly defined during the process of demyelination-remyelination.

The focal demyelination model is a useful tool to investigate the cellular response and molecular mechanisms during the demyelination-remyelination process as well as to screen and evaluate potential clinical treatments [23-25]. Focal demyelination models cannot recapitulate the complex pathophysiological changes and clinical effects of MS. However, localized injections of specific reagents create a highly reproducible lesion resembling the temporal profile of demyelination and spontaneous remyelination and creating predictable behavior dysfunction by generating a lesion in a predetermined location and precise size [24-27]. L- $\alpha$-Lysophosphatidylcholine (lysolecithin or LPC) creates a focal demyelination lesion with a specific temporal profile and well-defined borders by directly dissolving phospholipid membranes and destroying myelin sheaths [27-29]. A significant loss of OLs and myelin occur within 1-3 days post-injection (dpi) after an LPC injection into the CNS white matter. Spontaneous remyelination is initiated between 7 and $14 \mathrm{dpi}$ and is completed by $28 \mathrm{dpi}$ depending on the lesion location and age of the animal [23, 29-31]. Unlike LPC that causes secondary inflammation after its cytotoxic effects, intraspinal injection of lipopolysaccharide (LPS), a toll-like receptor (TLR)-4 agonist, induces rapid neuroinflammation with the activation and polarization of $\mathrm{M} / \mathrm{M}$ as well as secretion of pro-inflammatory cytokines, nitric oxide, and eicosanoids, resulting in prominent demyelination plaques with features of pattern III lesions of MS [26, 32, 33]. Demyelination appears at the injection site within 5-7 dpi and persists for 9-14 dpi with spontaneous remyelination occurring by $28 \mathrm{dpi}[26,32]$. While LPC and LPS are commonly used to create focal demyelination models, little is known about their temporal characteristics, differences in $\mathrm{M} / \mathrm{M}$ activation/polarization, and $\mathrm{OPC} / \mathrm{OL}$ migration/differentiation during demyelination and spontaneous remyelination. Considering the crucial roles of $\mathrm{M} / \mathrm{M}$ in neuroinflammation and the activity of $\mathrm{OPC} / \mathrm{OL}$ in the demyelination-remyelination process, lack of this information impedes the understanding of underlying mechanisms leading to the specific characteristics of these lesions.

In this study, we examined the temporal patterns (histology and in vivo monitoring) and neurobehavioral changes during demyelination and spontaneous remyelination in two focal demyelination models (LPC and LPS) that represent different features of MS. The detailed dynamic characteristics of $\mathrm{M} / \mathrm{M}$ activation/polarization, $\mathrm{OPC} / \mathrm{OL}$ response, and relevant neuroinflammatory cytokines during the processes of demyelination-remyelination may provide novel targets for efficient remyelination in the treatment of MS.

\section{Methods}

\section{Focal demyelination surgery}

Female C57BL/6 J mice (Jackson Laboratory, Bar Harbor, $\mathrm{ME)}$ were bred onsite and randomly assigned into three groups (control, LPC, and LPS groups) for surgery at 8 weeks of age $(18.97 \pm 1.02 \mathrm{~g})$. Surgery to create a focal demyelination lesion was modified based on our previous reports [24, 25]. After being deeply anesthetized with 2,2,2-Tribromoethanol $(300 \mathrm{mg} / \mathrm{kg} / \mathrm{i}$.p.; Sigma- 
Aldrich, St. Louis, MO), the C3-C5 spinal cord level was exposed by separating muscles and adipose tissues, removing the C3-5 laminae and ligamentum flavum, and opening dura using a surgical microscope. Focal demyelination lesions were created by stereotaxic injections into the dorsal funiculus at $\mathrm{C} 3-4$ and $\mathrm{C} 4-5$ using a pulled glass micropipette attached to a $10 \mu \mathrm{l}$ Hamilton syringe (Hamilton Company, Reno, NV) connected to an infusion pump. Then, $1 \mu \mathrm{l}$ of LPS $(0.1 \mathrm{mg} / \mathrm{ml}, 0.01 \%$; from Salmonella enterica serotype abortus equi; SigmaAldrich) or LPC (10 mg/ml, 1\%; Type I; Sigma-Aldrich) was injected into both sides along the midline into the dorsal columns at a rate of $0.2 \mu \mathrm{l} / \mathrm{min}$, and the micropipette was maintained in the dorsal columns for $2 \mathrm{~min}$ after each injection to avoid reflux. The control (CTR) group was injected with the same volume of sterile phosphate-buffered saline (PBS; Gibco, Carlsbad, CA) at the same rate as the vehicle group for both LPC and LPS groups. The muscle and adipose tissues were closed with a single suture, and the skin incision was closed with either rodent wound clips or suture (the latter used in mice scheduled for diffusion tensor imaging [DTI]). Each mouse was given saline $(1 \mathrm{ml} / \mathrm{s.c.}$; Nova-tech, Grand Island, NE) to prevent dehydration, buprenorphine hydrochloride $(0.1 \mathrm{mg} / \mathrm{kg} /$ s.c.; Par Pharmaceuticals, Rochester, MI) for postoperative analgesia, and gentamycin $(2 \mathrm{mg} / \mathrm{kg} / \mathrm{s.c}$.; Henry Schein Animal Health, Dublin, $\mathrm{OH}$ ) for antibiotic prophylaxis every $12 \mathrm{~h}$ for 3 days. Performance of behavioral assessments and tissue collections followed a specific protocol (Fig. 1).

\section{Tissue processing}

To obtain tissues for cryostat sectioning, mice were deeply anesthetized and killed by intracardiac perfusion with cold PBS (Gibco) and then 4\% (w/v) paraformaldehyde (SigmaAldrich) at 3, 5, 7, 10, 14, and 21 dpi. The C2-T2 spinal cord segment was dissected and maintained on ice, followed by overnight post-fixation in $4 \%(\mathrm{w} / \mathrm{v})$ paraformaldehyde at $4{ }^{\circ} \mathrm{C}$. Spinal cords were cryoprotected in
20\% (w/v) sucrose (RPI Research Products International Corp., Mount Prospect, IL) for $24 \mathrm{~h}$ at $4{ }^{\circ} \mathrm{C}$ and embedded in Tissue-Tek O.C.T. Compound (Sakura Finetek; Torrance, CA) for cryostat preparation. Transverse serial sections of $20 \mu \mathrm{m}$ thickness were cut on a cryostat (Leica Biosystems Inc., Buffalo Grove, IL) for luxol fast blue (LFB) staining and immunohistochemistry. To collect tissues for ribonucleic acid (RNA) extraction, mice were deeply anesthetized and killed by intracardiac perfusion with cold PBS rinse at 1, 7, and $14 \mathrm{dpi}$. Fresh C3-C5 spinal cord segments (epicenter) were immediately dissected out on ice and snap-frozen in liquid nitrogen before being stored at $-80{ }^{\circ} \mathrm{C}$. The frozen spinal cord segment was homogenized and lysed in RLT buffer supplemented with 2-mercaptoethanol (Sigma-Aldrich), followed by RNA extraction using the QIAshredder (Qiagen, Germantown, MD) and RNeasy Mini Kit (Qiagen).

\section{Luxol fast blue staining and quantitative analysis}

Myelin integrity was evaluated by LFB staining at 3, 5, 7, 10,14 , and $21 \mathrm{dpi}$ as a standard histochemical method to stain myelin. Cryostat sections were incubated in $0.1 \%(\mathrm{w} / \mathrm{v})$ LFB (Sigma-Aldrich) solution at $65{ }^{\circ} \mathrm{C}$ for $2 \mathrm{~h}$ after serial dehydration in ethanol solutions (Decon Labs, King of Prussia, PA). The sections were immersed in $0.05 \%(\mathrm{w} / \mathrm{v})$ lithium carbonate (Sigma-Aldrich) solution and rinsed in $70 \%$ ethanol, followed by serial dehydration in ethanol solutions. The slides were cleansed in Xylene (Sigma-Aldrich) and mounted with Xylene-based mounting medium (Richard-Allan Scientific/Thermo Scientific, Waltham, MA) for microscopic visualization (Nikon Instruments, Inc., Melville, NY). To demonstrate the severity of the demyelination lesion, the integrated optical density (IOD) of the dorsal column at the epicenter level was measured and divided by the dorsal column area at the same level (i.e., ROI) to achieve its optical density (OD) value with ImageJ software (http://imagej. nih.gov/ij/; NIH, Bethesda, MD) (Fig. 2b, first equation). The OD ratio of the dorsal column OD value divided by

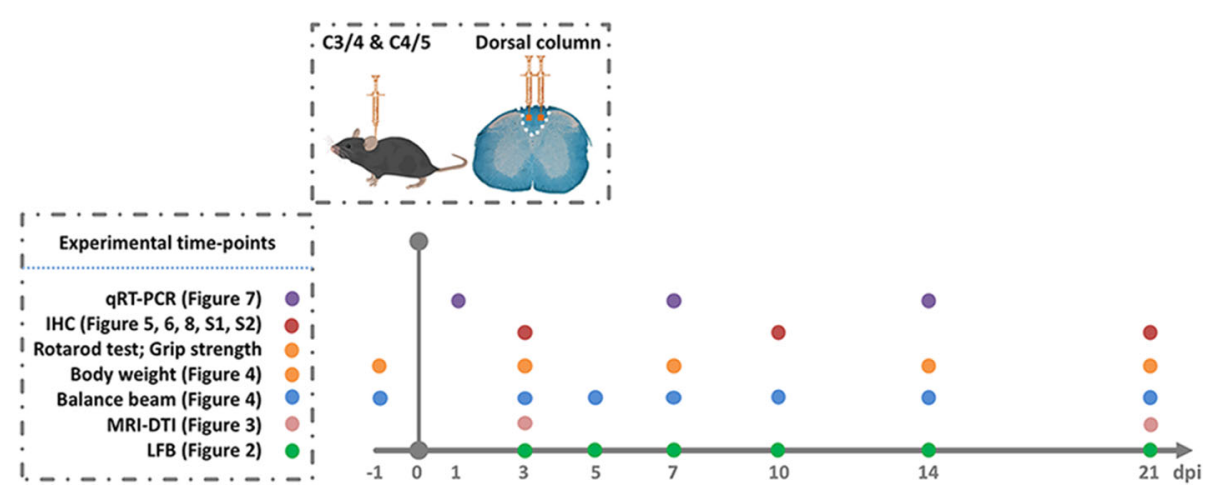

Fig. 1 Graphic illustration of the experimental protocol at different time-points 
the lateral column OD value on the same section was applied for normalization of the demyelination lesion in the dorsal column (Fig. 2b, second equation). The mean OD ratio of three epicenter sections was calculated for each mouse, which was considered as the observed value for group comparisons. Three mice per group at each time-point were used to examine group differences and time effects.

\section{Immunohistochemistry and quantitative analysis}

Double immunohistochemistry on cryostat sections was performed based on our previous reports [34-36], and antibodies applied in this study are listed in Additional file 1: Table S1. Microwave-based antigen retrieval was performed in an antigen unmasking solution (citric acid based; Vector Laboratories, Burlingame, CA) for certain antibodies (as indicated in in Additional file 1: Table S1) to achieve better signals. For GFAP/CD68 staining, each staining area divided by the dorsal column area was quantified with ImageJ (positive-labeling area fraction), and mean positive-labeling area fraction of two epicenter fields $(\times 10$ magnification) was calculated for each mouse. Mean values from three mice per group at each time-point were used to examine group differences

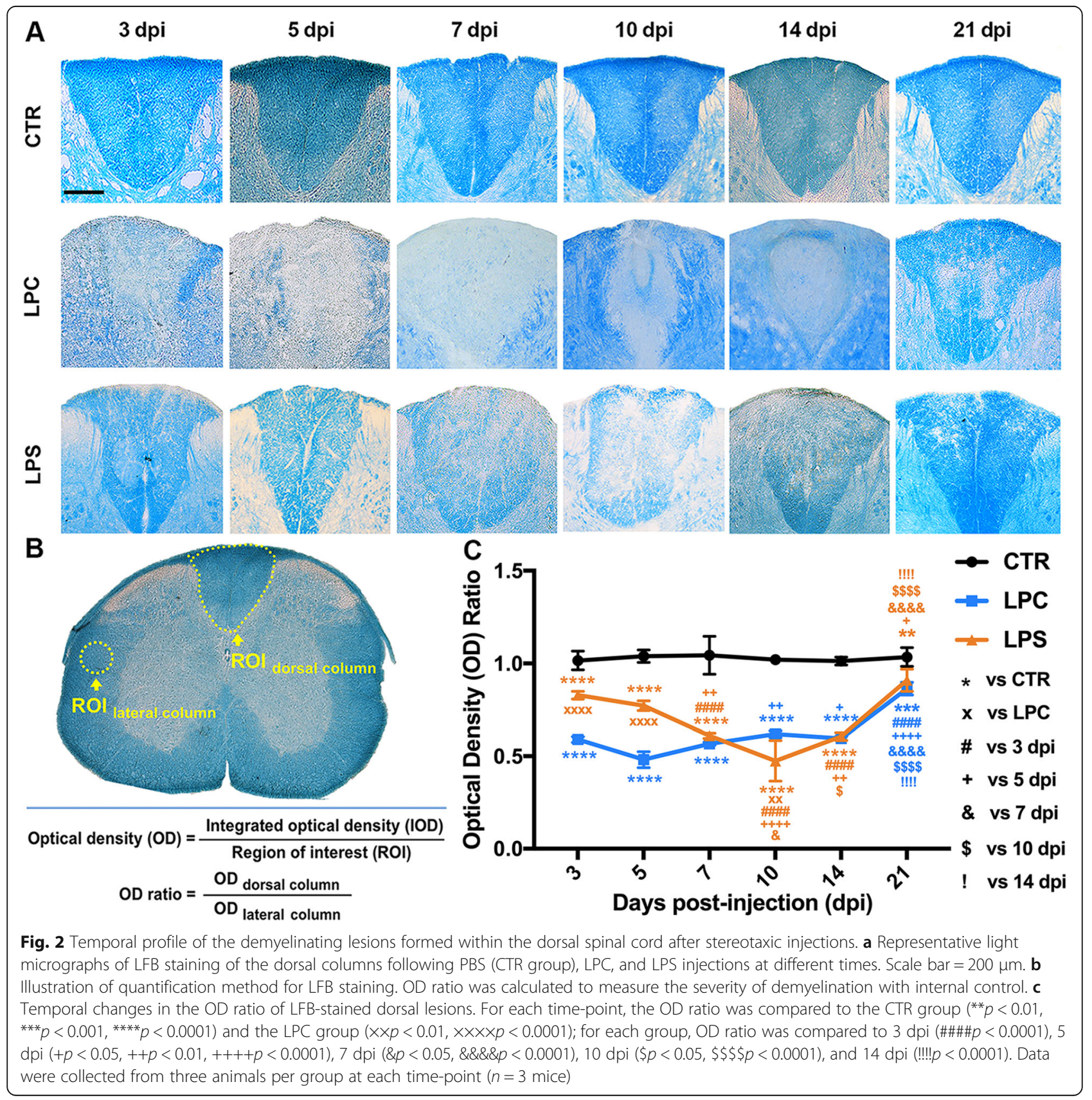


and time effects. For the other co-staining, positive cells within the dorsal column area were manually counted using ImageJ and expressed as cell number per square millimeter (cell density). Mean cell density of three epicenter fields ( $\times 20$ magnification) was calculated for each mouse. Mean values from three mice per group at each time-point were used for statistical analysis on group differences and time effects.

\section{Real-time quantitative reverse transcription polymerase chain reaction}

Gene expression was quantified by TaqMan gene expression assays (Applied Biosystems, Foster City, CA; as listed in in Additional file 2: Table S2) and TaqMan fast virus 1step master mix (Applied Biosystems) following the manufacturer's instructions. A total of 100 ng RNA from a fresh spinal cord segment (epicenter) was used per reaction. Real-time quantitative reverse transcription polymerase chain reaction (qRT-PCR) was conducted with Roche LightCycler 96 System (Roche, Branchburg, NJ), and Cq values were obtained and normalized to an endogenous reference ( $\beta$-actin, $A C T B)$ for relative quantification. Relative gene expression changes compared to the vehicle group at different time-points $(1,7,14 \mathrm{dpi})$ were analyzed using the $2^{-\triangle \Delta C q}$ method in a blinded manner $[37,38]$. Data were collected and mean values were calculated from four mice per group at each time-point.

\section{Magnetic resonance imaging-diffusion tensor imaging}

The MRI-DTI method and analysis were developed to detect the integrity of white matter (WM) microstructure based on the direction and magnitude of water diffusion [39-41]. Real-time monitoring was performed at the University of Louisville In Vivo Molecular Imaging Center using the Agilent $9.4 \mathrm{~T} / 31 \mathrm{~cm}$ horizontal bore magnetic resonance imaging )(MRI system equipped with a 205/120 high-duty (HD) gradient coil (Agilent, Santa Clara, CA). As a noninvasive/live-monitoring technique that measures the direction and magnitude of water diffusion [42, 43], diffusion tensor imaging (DTI) targeting on mouse cervical spinal cords was performed at 3,10 , and $21 \mathrm{dpi}$ after PBS, LPC, or LPS injection for detection and quantification of dorsal WM integrity. The affected segments (between C3-C5) were outlined as the epicenter for analysis. DTI metric parameters were obtained using DTIStudio (Johns Hopkins University, Baltimore, MD). Regions of interest (ROIs) were drawn and quantified using ImageJ software based on the anatomical landmarks of the MR images and mouse spinal cord atlas. DTI metrics of dorsal WM at the epicenter, including fractional anisotropy (FA), mean diffusivity $(\mathrm{MD})$, axial diffusivity $\left(\lambda_{\mathrm{Il}} ; \mathrm{AD}\right)$, and radial diffusivity $\left(\lambda_{\perp} ; \mathrm{RD}\right)$, were analyzed on the $78 \times 78 \mu \mathrm{m}^{2}$ inplane pixel resolution images to characterize the changes in microstructural integrity, cellularity/edema/necrosis, axonal damage, and demyelination or dysmyelination. Mean FA, MD, AD, and RD of four epicenter images were calculated for each mouse. Mean values from three mice per group at each time-point were used for statistical analysis on group comparisons and time effects.

\section{Behavioral assessment}

Demyelination lesions within the dorsal funiculi elicit possible functional alterations in mice. A series of behavioral assessments were conducted to evaluate mouse sensorimotor function at the pre-surgery stage (baseline) $(-1 \mathrm{dpi})$, early stage $(3,5 \mathrm{dpi})$, middle stage $(7,14 \mathrm{dpi})$, and late stage (21 dpi) to reveal the time-course of functional characteristics of LPC and LPS-induced dorsal demyelination. Body weight was recorded at the same time-points to monitor the body condition/health status of mice after surgery. The functional status was assessed by Rotarod performance, grip strength, and balance beam walking. Data were collected and mean values were calculated from nine mice per group with experimenter blinding.

\section{Rotarod performance}

This test evaluates locomotor function and coordination and was performed on the RotaRod (UgoBasile 7650 accelerating RotaRod, Varese, Italy) as described previously [34, 44]. In brief, a 2-day training/test regimen was followed with acceleration from 4 to $40 \mathrm{rpm}$ in $300 \mathrm{~s}$. The running time on the rod was recorded until the mouse fell off, and the average time of three trials on the test day was calculated as the Rotarod score. For each mouse, the Rotarod score to its baseline score (percent) was used for analysis to avoid functional variation between mice.

\section{Forelimb/grip strength}

This test was used to measure mouse forelimb/grip strength with a low-force testing system (ALMEMO, Woodland Hills, CA) and was conducted as described in our previous study [34]. The maximum pulling force (grams) of both forelimbs was digitally captured and recorded. The average value of three trials for each mouse was considered to be its forelimb/grip strength. The percentage of individual forelimb/grip strength to its baseline was calculated for analysis to avoid functional variation between mice.

\section{Balance beam}

This test evaluates fine sensorimotor function [45-47], and the method was modified based on previous reports $[48,49]$. The mouse was allowed to cross an elevated (30 $\mathrm{cm}$ above the table top) square beam $(50 \mathrm{~cm}$ in length) to reach the finish point, and the number of foot slips were recorded manually by two observers 
positioned on each side of the beam. Beam width ranged from 4 to $20 \mathrm{~mm}$ in five widths $(4,8,12,16$, and $20 \mathrm{~mm}$ ). Basic scores were based on whether the mouse could remain on the beam as follows: $4 \mathrm{~mm}=25$ points, $8 \mathrm{~mm}=20$ points, $12 \mathrm{~mm}=15$ points, $16 \mathrm{~mm}=10$ points, and $20 \mathrm{~mm}=5$ points. Pre-training was necessary for mice to achieve a stable and accurate performance. Four trials were performed on the test day with attention paid to (1) the beam width the mouse could transverse and (2) the number of foot slips in each trial (Final score $=$ Basic score - Average number of foot slips for a total of four trials). The percentage of the individual balance beam score to its baseline was calculated for analysis to avoid functional variation between mice.

\section{Statistics}

Data are expressed as mean \pm standard deviation (SD). Comparisons between the groups (LPC vs. CTR; LPS vs. CTR; LPS vs. LPC) at different time-points were analyzed by two-way analysis of variance (ANOVA), followed by Tukey's multiple comparisons test. Repeated measures two-way ANOVA was used for analyzing DTI metrics and behavioral assessments, followed by Tukey's multiple comparisons test. The linear regression models and Pearson correlation coefficients were used to examine the correlations between two variables (behavior vs. myelin integrity; $M / M$ subpopulation vs. myelin integrity). All statistical analyses were performed using GraphPad Prism 7.0 (GraphPad Software, San Diego, CA). The significance level was set at 0.05 for all comparisons.

\section{Results}

\section{Temporal lesion patterns in LPC- and LPS-induced focal} demyelination

As shown by LFB staining, the control group showed no signs of demyelination or changes in the OD ratio at any time-point. A rapid and robust loss of myelin occurred within the dorsal columns caused by LPC-induced demyelination which persisted until 21 dpi (Fig. 2a). Severe demyelination was observed throughout the early stage, and the OD ratio markedly declined at $3 \mathrm{dpi}$ compared to the control group (0.59 in LPC vs. 1.02 in CTR, $p<0.0001$ ), with an apparent trend toward a further decrease at $5 \mathrm{dpi}$ (Fig. 2c; 0.48 in LPC vs. 1.04 in CTR, $p<0.0001$ ). OD ratios remained decreased at the middle and late stages compared to the control group (Fig. 2c). However, gradual remyelination started at the middle stage (Fig. 2a, c; LPC: 0.62 at $10 \mathrm{dpi}$ vs. 0.48 at $5 \mathrm{dpi}, p<0.01$ ), and evident recovery was achieved at $21 \mathrm{dpi}$ (Fig. 2a, c; LPC: 0.86 at 21 dpi vs. 0.48 at $5 \mathrm{dpi}, p<0.0001)$. For the LPS group, mild myelin loss was identified by LFB staining in the early stage with OD ratios statistically lower than those of the control group ( 3 dpi: 0.83 in LPS vs. 1.02 in CTR, $p<$ 0.0001; 5 dpi: 0.77 in LPS vs. 1.04 in CTR, $p<0.0001$ ) but higher than those of the LPC group ( 3 dpi: 0.83 in LPS vs. 0.59 in LPC, $p<0.0001 ; 5$ dpi: 0.77 in LPS vs. 0.48 in LPC, $p<0.0001)$. During the middle stage, the severity of demyelination became more marked (Fig. 2a), and the OD ratios declined significantly compared to 3 dpi (LPS: 0.61 at $7 \mathrm{dpi}$ vs. 0.83 at $3 \mathrm{dpi}, p<0.0001$ ), with the lowest value at $10 \mathrm{dpi}$ (Fig. 2c; LPS: 0.47 at $10 \mathrm{dpi}$ vs. 0.83 at $3 \mathrm{dpi}, p<$ 0.0001). Similar to the LPC lesion, the OD ratio was statistically decreased compared to the control group (21 dpi: 0.91 in LPS vs. 1.04 in CTR, $p<0.01)$, significant remyelination was observed at $21 \mathrm{dpi}$ (Fig. 2a, c; LPS: 0.91 at 21 dpi vs. 0.47 at $10 \mathrm{dpi}, p<0.0001)$.

\section{White matter integrity detected by MRI-DTI}

In the representative trans-axial T2-weighted MR images (Fig. 3a), high signal intensity was seen in the LPC and LPS groups at 3 and $10 \mathrm{dpi}$, respectively. This might be a reflection of severe demyelination and/or inflammationinduced focal swelling in the spinal cord. FA was reduced at 3, 10, and 21 dpi after LPC injection (Fig. 3d; 3 dpi: 0.52 in LPC vs. 0.80 in CTR, $p<0.0001 ; 10$ dpi: 0.55 in LPC vs. 0.82 in CTR, $p<0.0001 ; 21$ dpi: 0.64 in LPC vs. 0.80 in CTR, $p<0.0001$ ), indicating a persistent disruption of dorsal column integrity. FA in the LPC at 21 dpi had significantly improved compared to 3 and $10 \mathrm{dpi}(0.64$ at $21 \mathrm{dpi}$ vs. 0.52 at $3 \mathrm{dpi}, p<0.0001 ; 0.64$ at $21 \mathrm{dpi}$ vs. 0.55 at 10 $\mathrm{dpi}, p<0.001)$, corresponding to the remyelination/integrity recovery that was confirmed by LFB staining of histological sections (Fig. 2). Although the MD values of the LPC group was slightly decreased compared to the control group, there were no significant changes compared to the control group at any stage (Fig. 3e), suggesting that no significant edema or necrosis occurred in the dorsal columns. AD was reduced (Fig. 3f; LPC vs. CTR: 0.0011 vs. 0.0015 at $3 \mathrm{dpi}, p<0.0001 ; 0.0011$ vs. 0.0016 at $10 \mathrm{dpi}, p<$ $0.0001 ; 0.0013$ vs. 0.0016 at $21 \mathrm{dpi}, p<0.001$ ) while $\mathrm{RD}$ was elevated (Fig. 3g; LPC vs. CTR: 0.00046 vs. 0.00027 at $3 \mathrm{dpi}, p<0.0001 ; 0.00044$ vs. 0.00026 at $10 \mathrm{dpi}, p<0.0001$; 0.00040 vs. 0.00028 at $21 \mathrm{dpi}, p<0.0001$ ) after LPC injection, indicating hindered water diffusion along the parallel axis of axons but increased water diffusion perpendicular to axons. This process was considered a consequence of demyelination or dysmyelination with axonal transport impairment [40, 50-52]. Similar to the change in FA, RD value at $21 \mathrm{dpi}$ was markedly attenuated $(0.00040$ at 21 dpi vs. 0.00046 at $3 \mathrm{dpi}, p<0.01 ; 0.00040$ at $21 \mathrm{dpi}$ vs. 0.00044 at $10 \mathrm{dpi}, p<0.05)$; but $\mathrm{AD}$ was declined at all the stages with a recovery trend (Fig. 3f, g). These values reflect the severe demyelination or dysmyelination induced by LPC at the early stage, followed by a gradual improvement at the late stage; however, the axonal transport was impaired from the early stage but had not yet recovered at the late stage. 





(See figure on previous page.)

Fig. $3 \mathrm{MRI-DTI}$ images and metrics of the demyelination lesion. a Representative MRI images of the mouse spinal cord acquired at the lesion level at 3, 10, and $21 \mathrm{dpi}$. Arrow indicates the dorsal injection sites for CTR, LPC, and LPS groups. Scale bar $=1000 \mu \mathrm{m}$. $\mathbf{b}$ Illustration of DTI metrics. c Illustration of alternations in DTI metrics under pathological conditions. $\mathbf{d}-\mathbf{g}$ DTI metrics FA, MD, $\lambda_{\|}, \lambda_{\perp}$, respectively of the dorsal spinal cord at the lesion level at 3, 10, and $21 \mathrm{dpi}$. For each time-point, the values were compared to the CTR group $\left({ }^{*} p<0.05,{ }^{* *} p<0.01,{ }^{* * *} p<0.001,{ }^{* * * *} p<\right.$

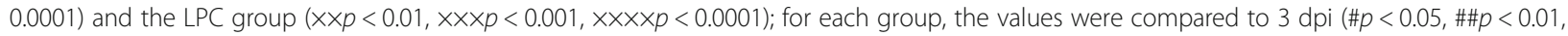
$\# \# \# p<0.001$, \#\#\#\# $<0.0001)$ and $10 \mathrm{dpi}(+p<0.05,++p<0.01,+++p<0.001)$. Data were collected from three animals per group at each timepoint ( $n=3$ mice)

For the LPS group, FA was significantly reduced at 3 and 10 dpi (Fig. 3d; 3 dpi: 0.64 in LPS vs. 0.80 in CTR, $p<$ 0.0001; 10 dpi: 0.64 in LPS vs. 0.82 in CTR, $p<0.0001$ ). Although FA in LPS at 21 dpi was still lower than the control group (0.72 in LPS vs. 0.80 in CTR, $p<0.01$ ), it had improved compared to 3 and 10 dpi $(0.72$ at 21 dpi vs. 0.64 at $3 \mathrm{dpi}, p<0.001 ; 0.72$ at $21 \mathrm{dpi}$ vs. 0.64 at $10 \mathrm{dpi}$, $p<0.01$ ), consistent with the improved remyelination/integrity found in LFB staining results (Fig. 2). FA in LPS was higher than that in LPC at all stages (3 dpi: 0.64 in LPS vs. 0.52 in LPC, $p<0.0001 ; 10$ dpi: 0.64 in LPS vs. 0.55 in LPC, $p<0.001 ; 21$ dpi: 0.72 in LPS vs. 0.64 in LPC, $p<0.01$ ), indicating that LPC causes more severe damage to the microstructural integrity. No statistical difference was detected in MD values between the control and LPS groups at any stage post-injection (Fig. 3e), suggesting that no significant edema or necrosis occurred in the dorsal columns. Compared to the control, RD in the LPS was elevated at $3 \mathrm{dpi}$ and worsened at $10 \mathrm{dpi}$ but significantly recovered at $21 \mathrm{dpi}$ (LPS vs. CTR: 0.00037 vs. 0.00027 at 3 dpi, $p<0.0001 ; 0.00042$ vs. 0.00026 at $10 \mathrm{dpi}, p<0.0001$; 0.00032 vs. 0.00028 at $21 \mathrm{dpi}, p<0.05$. LPS: 0.00032 at 21 dpi vs. 0.00037 at $3 \mathrm{dpi}, p<0.05 ; 0.00032$ at $21 \mathrm{dpi}$ vs. 0.00042 at $10 \mathrm{dpi}, p<0.001)$ while $\mathrm{AD}$ was reduced at all the stages only with a recovery trend (LPS vs. CTR: 0.0012 vs. 0.0015 at $3 \mathrm{dpi}, p<0.001 ; 0.0014$ vs. 0.0016 at $10 \mathrm{dpi}$, $p<0.01 ; 0.0014$ vs. 0.0016 at $21 \mathrm{dpi}, p<0.05)$ in the LPS group (Fig. 3f, g). These values reflect the LPS-induced demyelination or dysmyelination starting from $3 \mathrm{dpi}$, severe at $10 \mathrm{dpi}$, followed by recovery at $21 \mathrm{dpi}$; however, the axonal transport was impaired from $3 \mathrm{dpi}$ but had not yet recovered at $21 \mathrm{dpi}$.

\section{Behavioral changes following the dorsal funicular demyelination}

Mouse body weight showed an acute loss in all groups at $3 \mathrm{dpi}$ compared to the pre-injection baseline (CTR: 0.95 at 3 dpi vs. 1.00 at pre-injection day, $p<0.05$; LPC: 0.93 at 3 dpi vs. 1.00 at pre-injection day, $p<0.0001$; LPS: 0.92 at $3 \mathrm{dpi}$ vs. 1.00 at pre-injection day, $p<$ 0.0001 ) but soon recovered. No significant difference was observed between groups at any time-point (Fig. 4a). Rotarod performance was assessed to evaluate mouse motor coordination and balance (Fig. 4b). Mice in the LPC group showed an apparent trend toward a decrease in the latency to fall from the Rotarod compared to the control mice at the early and middle stages. However, no statistical difference was found between the LPC or LPS group and CTR group, indicating that no major deficit in motor coordination function was induced by dorsal demyelination. Forelimb/grip strength was measured to show whether dorsal demyelination affected neuromuscular strength (Fig. 4c). In comparison to pre-injection baseline, grip strength showed an acute decrease in all groups (CTR: 0.86 at 3 dpi vs. 1.00 at pre-injection day, $p<0.01$; LPC: 0.81 at 3 dpi vs. 1.00 at pre-injection day, $p<0.001$; LPS: 0.88 at 3 dpi vs. 1.00 at pre-injection day, $p<$ $0.05)$, all of which gradually resolved over time. Similar to the alterations in body weight, this initial decrease was probably caused by an acute reaction to surgery which could be further exacerbated by demyelination. No significant difference was detected between all groups. This data indicated that neuromuscular strength was not significantly affected by the dorsal demyelination lesions. To reveal fine deficits in mouse sensorimotor function, balance beam testing was conducted at several time-points $(-1,3,5,7,10,14$, and $21 \mathrm{dpi}$ ). The control group showed a consistent balance beam score without any statistical differences at all time-points, while both LPC and LPS groups exhibited significant decreases at all time-points except at $21 \mathrm{dpi}$ (Fig. 4d). For the LPC group, the balance beam score dropped at $3 \mathrm{dpi}$ (3 dpi: 0.71 in LPC vs. 0.92 in CTR, $p<0.0001$; LPC: 0.71 at $3 \mathrm{dpi}$ vs. 1.00 at pre-injection day, $p<0.0001)$, reached the lowest level at $5 \mathrm{dpi}(5 \mathrm{dpi}$ : 0.65 in LPC vs. 0.99 in CTR, $p<0.0001$; LPC: 0.65 at 5 dpi vs. 1.00 at pre-injection day, $p<0.0001$ ), and gradually improved up to $21 \mathrm{dpi}$ when there was no significant difference compared to CTR or pre-injection baseline (21 dpi: 0.93 in LPC vs. 0.97 in CTR, $p>0.05$; LPC: 0.93 at $21 \mathrm{dpi}$ vs. 1.00 at pre-injection day, $p>$ 0.05). Similarly, mice in the LPS group showed a significant decrease in balance beam score at 3 dpi $(3 \mathrm{dpi}$ : 0.75 in LPS vs. 0.92 in CTR, $p<0.001$; LPS: 0.75 at 3 dpi vs. 1.00 at pre-injection day, $p<0.0001)$, reached its lowest level during the middle stage ( $7 \mathrm{dpi}: 0.68$ in LPS vs. 0.99 in CTR, $p<0.0001$; LPS: 0.68 at 7 dpi vs. 1.00 at pre-surgery day, $p<0.0001 ; 10 \mathrm{dpi}: 0.71$ in LPS vs. 1.01 in CTR, $p<0.0001$; LPS: 0.71 at $10 \mathrm{dpi}$ vs. 1.00 at 

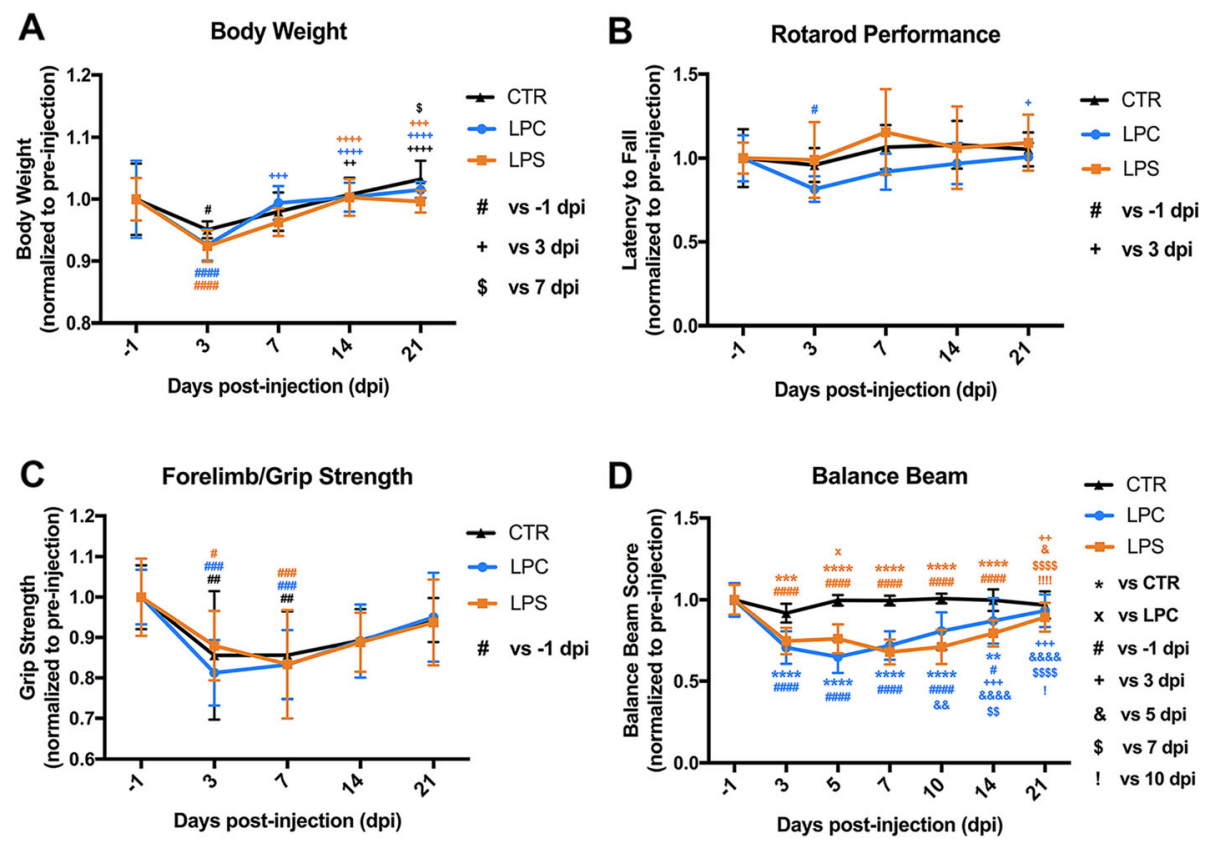

Fig. 4 Temporal changes in the neurobehavioral performance of dorsal demyelination mouse models. a Body weight (normalized to each baseline at $-1 \mathrm{dpi}$ ) changes at different time-points after focal injection of PBS, LPC, and LPS into the dorsal column of the spinal cord. For each time-point, no statistical significance in body weight between the LPC/LPS groups and CTR group was noted; for each group, body weight was compared to $-1 \mathrm{dpi}(\# p<0.05$, \#\#\#\#< 0.0001), $3 \mathrm{dpi}(++p<0.01,+++p<0.001,++++p<0.0001), 7 \mathrm{dpi}(\$ p<0.05)$, and $14 \mathrm{dpi}$ (no statistical significance for all groups). $\mathbf{b}$ Rotarod performance (normalized to each baseline at $-1 \mathrm{dpi}$ ) at different time-points. No statistical significance between the LPC or LPS group and CTR group were observed at any given time-point; for each group, no statistical significance between different time-points except when compared to $-1 \mathrm{dpi}(\# p<0.05)$ and $3 \mathrm{dpi}(+p<0.05)$ in LPC group. c Grip strength (normalized to each baseline at $-1 \mathrm{dpi}$ ) at different time-points. For each time-point, no statistical significance in forelimb/grip strength was noted between the LPC/ LPS groups and CTR group; for each group, no statistical significance between different time-points except when compared to $-1 \mathrm{dpi}$ (\#p $<0.05$, $\# \# p<0.01$, \#\#\# < 0.001). d Balance beam score (normalized to each baseline at $-1 \mathrm{dpi}$ ) at different time-points. For each time-point, the balance beam score was compared to the CTR group $\left({ }^{* * *} p<0.001,{ }^{* * *} p<0.0001\right)$ and the LPC group $(\times p<0.05)$; for each group, balance beam score was compared to $-1 \mathrm{dpi}(\# p<0.05$, \#\#\#\#p < 0.0001), $3 \mathrm{dpi}(++p<0.01,++++p<0.0001), 5 \mathrm{dpi}(\& p<0.05, \& \& p<0.01, \& \& \& \& p<0.0001), 7 \mathrm{dpi}$ $(\$ \$ p<0.01, \$ \$ \$ p<0.0001), 10 \mathrm{dpi}(! p<0.05, ! ! ! ! p<0.0001)$, and $14 \mathrm{dpi}$ (no statistical significance for all groups). Data were collected from nine animals per group ( $n=9$ mice) with experimenter blinding

pre-injection day, $p<0.0001)$, and then gradually recovered by $21 \mathrm{dpi}$ ( $21 \mathrm{dpi}$ : 0.90 in LPS vs. 0.97 in CTR, $p>$ 0.05; LPS: 0.90 at $21 \mathrm{dpi}$ vs. 1.00 at pre-injection day, $p>0.05)$.

\section{Response of oligodendrocyte-linage cells following demyelination}

To examine the dynamic response of OPCs that determines the demyelination-remyelination process, cell densities of $\mathrm{Olig}^{+}{ }^{+} \mathrm{Pdgfr}^{+}$cells (OPCs; Fig. 5) and $\mathrm{Pdgfra}^{+} \mathrm{Ki} 67^{+}$cells (proliferative OPCs; in Additional file 3: Figure S1 A and D) within the dorsal column were examined at early ( $3 \mathrm{dpi})$, middle $(10 \mathrm{dpi})$, and late $(21 \mathrm{dpi})$ stages. In LPC-induced focal lesions, adult Olig2 ${ }^{+}$Pdgfra $^{+}$ OPCs aggregated along the margin around the epicenter at $3 \mathrm{dpi}$ and further migrated into the lesion area at 10 dpi. In contrast, OPCs showed a diffuse pattern within the dorsal column and adjacent gray matter in LPS-induced lesions (Fig. 5a). OPCs presented in the control spinal cord at a low density throughout all time-points. After focal LPC or LPS injections, the density of OPCs significantly increased at $3 \mathrm{dpi}\left(112.00\right.$ cells $/ \mathrm{mm}^{2}$ in LPC vs. 39.18 cells $/ \mathrm{mm}^{2}$ in CTR, $p<0.0001 ; 154.40$ cells $/ \mathrm{mm}^{2}$ in LPS vs. 39.18 cells $/ \mathrm{mm}^{2}$ in CTR, $\left.p<0.0001\right)$, reached the peak at $10 \mathrm{dpi}\left(268.20\right.$ cells $/ \mathrm{mm}^{2}$ in LPC vs. 34.90 cells/ $\mathrm{mm}^{2}$ in CTR, $p<0.0001 ; 180.50$ cells $/ \mathrm{mm}^{2}$ in LPS vs. 34.90 cells $/ \mathrm{mm}^{2}$ in CTR, $p<0.0001$ ), and declined at 21 dpi $\left(121.30\right.$ cells $/ \mathrm{mm}^{2}$ in LPC vs. 38.72 cells $/ \mathrm{mm}^{2}$ CTR, $p<0.0001 ; 63.27$ cells $/ \mathrm{mm}^{2}$ in LPS vs. 38.72 cells $/ \mathrm{mm}^{2}$ in CTR, $p<0.05$ ) (Fig. 5b). In addition to the OPC recruitment in focal demyelination lesions, proliferative OPCs were significantly increased within the dorsal column after 3 dpi (Additional file 3: Figure S1 A and D). In LPCinduced lesions, the proliferative Pdgfro ${ }^{+} \mathrm{Ki} 67^{+}$OPCs erupted at 3dpi (Pdgfro ${ }^{+} \mathrm{Ki}^{+} 7^{+} ; 63.19$ cells $/ \mathrm{mm}^{2}$ in LPC vs. 0 cells $/ \mathrm{mm}^{2}$ in CTR, $p<0.0001$ ) and progressively decreased at $10 \mathrm{dpi}\left(47.80\right.$ cells $/ \mathrm{mm}^{2}$ in LPC vs. 0 cells $/ \mathrm{mm}^{2}$ in CTR, $p<0.0001)$ and $21 \mathrm{dpi}\left(21.56\right.$ cells $/ \mathrm{mm}^{2}$ in LPC vs. 0 cells $/ \mathrm{mm}^{2}$ in CTR, $\left.p<0.001\right)$. The proliferative OPCs were also increased at $3 \mathrm{dpi}\left(30.22\right.$ cells $/ \mathrm{mm}^{2}$ in LPS vs. 0 


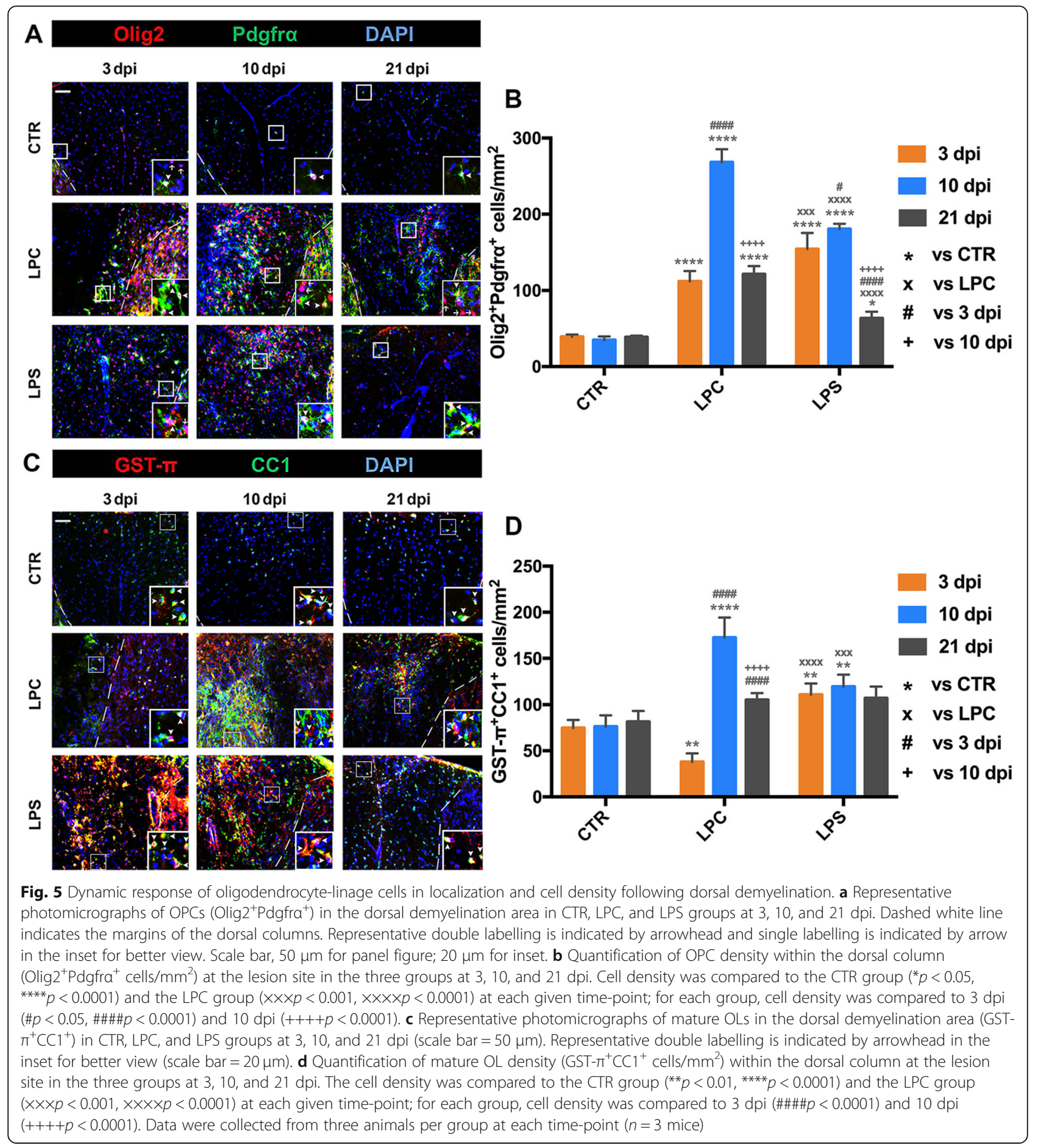

cells $/ \mathrm{mm}^{2}$ in CTR, $\left.p<0.0001\right)$ in LPS-induced lesions. The peak of proliferation of OPCs occurred at $10 \mathrm{dpi}$ (62.06 cells $/ \mathrm{mm}^{2}$ in LPS vs. 0 cells $/ \mathrm{mm}^{2}$ in CTR, $p<$ $0.0001)$, followed by a decrease at $21 \mathrm{dpi}\left(15.13\right.$ cells $/ \mathrm{mm}^{2}$ in LPS vs. 0 cells $/ \mathrm{mm}^{2}$ in CTR, $p<0.01$ ).

To determine the temporal characteristics of OPC differentiation within the dorsal column, GST- $\pi^{+} \mathrm{CC}^{+}$ (differentiated/mature) oligodendrocytes within the dorsal column were counted at early ( $3 \mathrm{dpi})$, middle $(10 \mathrm{dpi})$, and late stages ( $21 \mathrm{dpi}$ ) (Fig. $5 \mathrm{c}, \mathrm{d})$. GST- $\pi^{+} \mathrm{CC}^{+}$cells were identified within the dorsal column at a relatively constant density with no significant changes between different time-points in the control group. For the LPC-induced lesion, the density of $\mathrm{GST}-\pi^{+} \mathrm{CC}^{+}$cells was significantly 
decreased at $3 \mathrm{dpi}$ (37.75 cells $/ \mathrm{mm}^{2}$ in LPC vs. 74.64 cells/ $\mathrm{mm}^{2}$ in CTR, $p<0.01$ ), with only few GST $-\pi^{+} \mathrm{CC}^{+}$cells spared from damage along the dorsal column margin and some in the adjacent GM. At $10 \mathrm{dpi}$, the density was greatly increased within the demyelination area (172.30 cells $/ \mathrm{mm}^{2}$ in LPC vs. 76.14 cells $/ \mathrm{mm}^{2}$ in CTR, $p<0.0001$ ), followed by a downregulation to the normal density at 21 dpi $\left(105.00\right.$ cells $/ \mathrm{mm}^{2}$ in LPC vs. 81.38 cells $/ \mathrm{mm}^{2}$ in CTR, $p>0.05)$. Notably, the distribution of differentiated oligodendrocytes from the dorsal column margin into the demyelination center was similar to that of OPCs at 10 dpi (Fig. 5a). For the LPS-induced lesion, GST $-\pi^{+} \mathrm{CC}^{+}$ cells were increased at $3 \mathrm{dpi}\left(110.80\right.$ cells $/ \mathrm{mm}^{2}$ in LPS vs. 74.64 cells $/ \mathrm{mm}^{2}$ in CTR, $\left.p<0.01\right)$ that were scattered within the dorsal columns and maintained at the similar level at $10 \mathrm{dpi}\left(119.50\right.$ cells $/ \mathrm{mm}^{2}$ in LPS vs. 76.14 cells/ $\mathrm{mm}^{2}$ in CTR, $p<0.01$ ), but returned to the normal range at $21 \mathrm{dpi}\left(106.90\right.$ cells $/ \mathrm{mm}^{2}$ in LPS vs. $81.38 \mathrm{cells} / \mathrm{mm}^{2}$ in CTR, $p>0.05)$.

\section{Response of astrocytes and microglia/macrophages following demyelination}

To characterize the temporal activity of astrocytes and microglia/macrophages $(\mathrm{M} / \mathrm{M})$, fractions of GFAP- or CD68-labeling area within the dorsal columns were quantified at 3,10 , and $21 \mathrm{dpi}$ after LPC or LPS injection (Fig. 6). The GFAP-labeling area fraction remained low in control mice at all time-points. GFAP-labeling area fraction was mildly decreased in the LPC mice but dramatically increased in the LPS mice at $3 \mathrm{dpi}(1.45 \%$ in LPC vs. $2.80 \%$ in CTR, $p>0.05 ; 12.36 \%$ in LPS vs. $2.80 \%$ in CTR, $p<0.0001 ; 1.45 \%$ in LPC vs. $12.36 \%$ in LPS, $p<$ 0.0001). At $10 \mathrm{dpi}$, GFAP-labeling area fraction reached the peak in the LPC mice $(17.05 \%$ in LPC vs. $2.79 \%$ in CTR, $p<0.0001)$ and the LPS mice $(14.68 \%$ in LPS vs. $2.79 \%$ in CTR, $p<0.0001)$. Both GFAP-labeling area fractions significantly decreased until $21 \mathrm{dpi}$, at which time it was still higher in LPC mice $(7.32 \%$ in LPC vs. $2.76 \%$ in CTR, $p<0.001)$ but returned to the control range in LPS mice (4.07\% in LPS vs. $2.76 \%$ in CTR, $p>$ 0.05). The CD68 immunoreactivity was almost undetectable in control mice at all time-points. CD68-labeling area fraction was rapidly increased in both LPC and LPS mice at $3 \mathrm{dpi}(7.84 \%$ in LPC vs. $0.17 \%$ in CTR, $p<$ $0.0001 ; 10.85 \%$ in LPS vs. $0.17 \%$ in CTR, $p<0.0001$; $7.84 \%$ in LPC vs. $10.85 \%$ in LPS, $p<0.05$ ). At $10 \mathrm{dpi}$, CD68-labeling area fraction reached the peak in the LPC mice $(24.51 \%$ in LPC vs. $0.17 \%$ in CTR, $p<0.0001$ ), as well as in the LPS mice $(14.29 \%$ in LPS vs. $0.17 \%$ in CTR, $p<0.0001)$. Similar to the changes in GFAPlabeling area fraction, both CD68-labeling area fractions were significantly reduced at $21 \mathrm{dpi}$, at which time it remained higher in LPC mice $(6.58 \%$ in LPC vs. $0.16 \%$ in
CTR, $p<0.0001)$ but returned to the control range in LPS mice (1.98\% in LPS vs. $0.16 \%$ in CTR, $p>0.05$ ).

In the LPC mice, cellular proliferation was robustly activated throughout all time-points in $\mathrm{M} / \mathrm{M}$ (Additional file 3: Figure $\mathrm{S} 1 \mathrm{~B}$ and $\mathrm{E}$ for $\mathrm{Iba} 1^{+} \mathrm{Ki} 67^{+} ; 3$ dpi: 55.95 cells $/ \mathrm{mm}^{2}$ in LPC vs. 0 cells $/ \mathrm{mm}^{2}$ in CTR, $p<0.0001 ; 10$ dpi: 145.30 cells $/ \mathrm{mm}^{2}$ in LPC vs. 0 cells $/ \mathrm{mm}^{2}$ in CTR, $p<0.0001 ; 21 \mathrm{dpi}: 23.80$ cells $/ \mathrm{mm}^{2}$ in LPC vs. 0 cells/ $\mathrm{mm}^{2}$ in CTR, $p<0.0001$ ) and astrocytes (Additional file 3: Figure $\mathrm{S} 1 \mathrm{C}$ and $\mathrm{F}$ for $\mathrm{GFAP}^{+} \mathrm{Ki}^{+}{ }^{+}$; 3 dpi: 28.28 cells $/ \mathrm{mm}^{2}$ in LPC vs. 0 cells $/ \mathrm{mm}^{2}$ in CTR, $p<0.0001 ; 10$ dpi: 26.87 cells $/ \mathrm{mm}^{2}$ in LPC vs. 0 cells $/ \mathrm{mm}^{2}$ in CTR, $p<$ $0.0001 ; 21$ dpi: 5.26 cells $/ \mathrm{mm}^{2}$ in LPC vs. 0 cells $/ \mathrm{mm}^{2}$ in CTR, $p>0.05$ ). However, $\mathrm{M} / \mathrm{M}$ showed much lower proliferation in LPS mice than in LPC mice (Additional file 3: Figure S1 B and E for $\mathrm{Iba}^{+} \mathrm{Ki}^{+} 7^{+}$; 3 dpi: 28.33 cells $/ \mathrm{mm}^{2}$ in LPS vs. 0 cells $/ \mathrm{mm}^{2}$ in CTR, $p<0.0001 ; 10$ dpi: 24.50 cells $/ \mathrm{mm}^{2}$ in LPS vs. 0 cells $/ \mathrm{mm}^{2}$ in CTR, $p<$ $0.0001 ; 21$ dpi: 8.10 cells $/ \mathrm{mm}^{2}$ in LPS vs. 0 cells $/ \mathrm{mm}^{2}$ in CTR, $p>0.05 .3$ dpi: 28.33 cells $/ \mathrm{mm}^{2}$ in LPS vs. 55.95 cells $/ \mathrm{mm}^{2}$ in LPC, $p<0.0001 ; 10$ dpi: 24.50 cells $/ \mathrm{mm}^{2}$ in LPS vs. 145.30 cells $/ \mathrm{mm}^{2}$ in LPC, $p<0.0001 ; 21 \mathrm{dpi}: 8.10$ cells $/ \mathrm{mm}^{2}$ in LPS vs. 23.80 cells $/ \mathrm{mm}^{2}$ in LPC, $p<0.001$ ). Astrocytes also significantly proliferated in LPS mice in the early and middle stages which was not observed at the late stage (Additional file 3: Figure S1 C and F for $\mathrm{GFAP}^{+} \mathrm{Ki}^{+} 7^{+} ; 3$ dpi: 35.51 cells $/ \mathrm{mm}^{2}$ in LPS vs. 0 cells/ $\mathrm{mm}^{2}$ in CTR, $p<0.0001 ; 10$ dpi: 17.04 cells $/ \mathrm{mm}^{2}$ in LPS vs. 0 cells $/ \mathrm{mm}^{2}$ in CTR, $p<0.001 ; 21$ dpi: 0 cells $/ \mathrm{mm}^{2}$ in LPS vs. 0 cells $/ \mathrm{mm}^{2}$ in CTR, $p>0.05$ ).

Activated and proliferating $\mathrm{M} / \mathrm{M}$ and astrocytes in LPC mice were observed mainly along the WM borders and directly adjacent to GM at $3 \mathrm{dpi}$. Then, $\mathrm{GFAP}^{+}$astrocytes with enlarged processes were visible within the demyelination area around the lesion core while $\mathrm{M} / \mathrm{M}$ were distributed throughout the entire demyelination lesion area. In contrast, all $\mathrm{M} / \mathrm{M}$ and astrocytes in LPS mice were disbursed throughout the lesion area and adjacent GM throughout all time-points (Fig. 6a, Additional file 3: Figure S1 B and C).

\section{Time-course expression of pro-inflammatory and anti- inflammatory cytokines}

To further confirm the inflammatory response and identify its potential role in the demyelination-remyelination process, the temporal expression levels of tumor necrosis factor alpha $(T N F \alpha)$ and $I L-1 \beta$ (pro-inflammatory cytokines) and IGF-1 and TGF- $\beta 1$ (anti-inflammatory cytokines) within the epicenter were examined at 1,7 , and $14 \mathrm{dpi}$ (Fig. 7). In the LPC mice, the relative expression ratio of $T N F \alpha$ was slightly increased at $1 \mathrm{dpi}$ with no significant difference compared to the control group (2.89 in LPC vs. 1.00 in CTR, $p>0.05$ ), then was significantly increased at $7 \mathrm{dpi}$ (6.54 in LPC vs. 1.00 in CTR, 




$p<0.01)$, and returned to the control levels at $14 \mathrm{dpi}$ (3.29 in LPC vs. 1.00 in CTR, $p>0.05$ ) (Fig. 7a). The relative expression of $I L-1 \beta$ gradually increased with a significance difference found at $14 \mathrm{dpi}$ (Fig. 7b; 8.29 in LPC vs. 1.00 in CTR, $p<0.001)$. Unlike LPC mice, the relative expression of both $T N F \alpha$ and $I L-1 \beta$ were dramatically upregulated and reached their peak levels at 1 dpi after LPS injection (Fig. 7a for TNF 0 : 46.79 in LPS vs. 1.00 in CTR, $p<0.0001$; Fig. $7 \mathrm{~b}$ for $I L-1 \beta$ : 29.54 in LPS vs. 1.00 in CTR, $p<0.0001)$. Both TNF $\alpha$ and $I L-1 \beta$ expression levels were then greatly downregulated at later stages, but $T N F \alpha$ expression remained moderately higher while $I L-1 \beta$ expression was not statistically different compared to the control (Fig. 7a for $T N F \alpha ; 7 \mathrm{dpi}$ : 6.76 in LPS vs. 1.00 in CTR, $p<0.01 ; 14$ dpi: 5.59 in LPS vs. 1.00 in CTR, $p<0.05$. Fig. $7 \mathrm{~b}$ for $I L-1 \beta$; $7 \mathrm{dpi}$ : 3.57 in LPS vs. 1.00 in CTR, $p>0.05$; 14 dpi: 3.24 vs. 1.00 in CTR, $p>0.05)$. However, the temporal changes in the expression of $I G F-1$ and $T G F-\beta 1$ were similar in LPC and LPS mice (Fig. 7c, d): slightly decreased or equivalent compared to the control mice at $1 \mathrm{dpi}$ and gradually increased at later stages.

\section{Temporal characteristics of M/M polarization and localization}

To determine the timing of $\mathrm{M} / \mathrm{M}$ polarization and localization pattern during the process of demyelination and remyelination, the densities of $\mathrm{CD}_{206}{ }^{+} \mathrm{Iba1}^{+}$(M2) and $\mathrm{CD} 16 / 32^{+} \mathrm{Iba}^{+}$(M1) cells at 3, 10, and 21 dpi were quantified within the dorsal column (Fig. 8). These findings were further confirmed by staining of $\operatorname{Arg} 1^{+} \mathrm{Iba} 1^{+}$ (M2) and $\mathrm{CD}^{+} 6^{+} \mathrm{Iba1}^{+}$(M1) cells (Additional file 4: Figure S2). M2 $\left(\mathrm{CD}_{206}{ }^{+} \mathrm{Iba}^{+}\right.$or $\left.\mathrm{Arg}^{+} \mathrm{Iba} 1^{+}\right)$or M1 (CD16/ $32^{+} \mathrm{Iba}^{+}$or $\mathrm{CD} 6^{+} \mathrm{Iba}^{+}$) cells were rarely detected throughout all time-points in the control mice. In the LPC mice, robust increases in the densities of $\mathrm{CD}_{206} \mathrm{Iba}^{+}$ cells $\left(163.00\right.$ cells $/ \mathrm{mm}^{2}$ in LPC vs. 3.32 cells $/ \mathrm{mm}^{2}$ in CTR, $p<0.0001)$ while $\mathrm{CD} 16 / 32^{+} \mathrm{Iba}^{+}$cells $\left(200.40\right.$ cells $/ \mathrm{mm}^{2}$ in LPC vs. 0 cells $/ \mathrm{mm}^{2}$ in CTR, $p<0.0001$ ) were observed within the spared dorsal margin at $3 \mathrm{dpi}$. Although both densities increased at $10 \mathrm{dpi}\left(\mathrm{CD}_{206}{ }^{+} \mathrm{Iba1}^{+}: 244.70\right.$ cells/ $\mathrm{mm}^{2}$ in LPC vs. 1.39 cells $/ \mathrm{mm}^{2}$ in CTR, $p<0.0001$; CD16/32 ${ }^{+} \mathrm{Iba}^{+}: 344.20$ cells $/ \mathrm{mm}^{2}$ in LPC vs. 0 cells $/ \mathrm{mm}^{2}$ in CTR, $p<0.0001$ ), different localization patterns were noted within the demyelination lesion at this time-point 


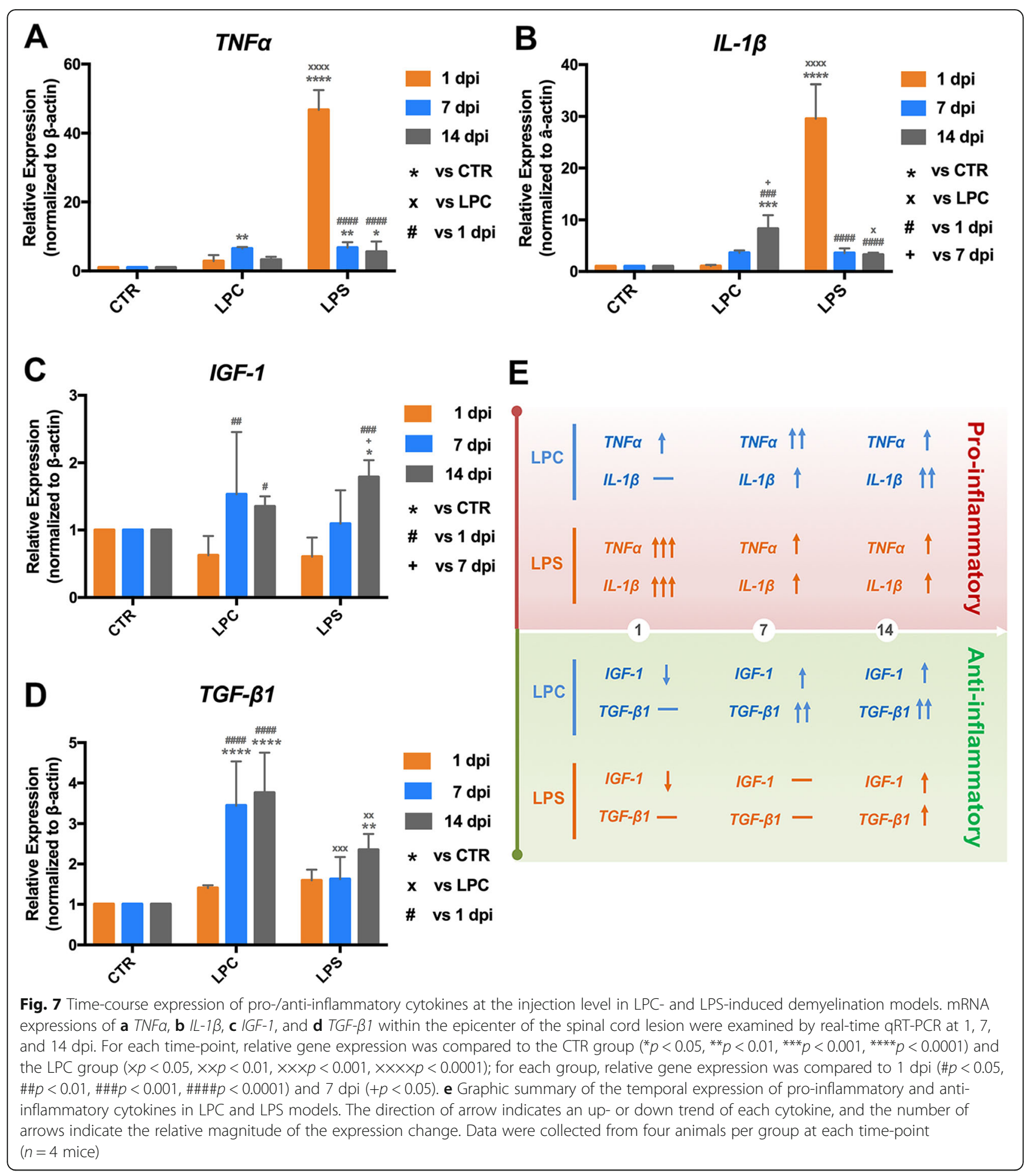

of initial remyelination. $\mathrm{CD} 206^{+} \mathrm{Iba1}^{+}$cells were concentrated within the demyelination lesion core (Fig. 8a), surrounded by oligodendrocyte-linage cells (Fig. 5a, c), astrocytes (Fig. 6a), and other M/M cells, including CD16/ $32^{+}$Iba1 $^{+}$cells (Fig. 8b). At 21 dpi, both $\mathrm{CD}^{2} 06^{+} \mathrm{Iba1}^{+}$cells and $\mathrm{CD} 16 / 32^{+} \mathrm{Iba}^{+}$cells were evenly distributed within the remaining lesion area, and their densities were both significantly reduced (especially the $\mathrm{CD} 16 / 32^{+} \mathrm{Iba} 1^{+}$cells) but still higher than those in the control mice $\left(\mathrm{CD}^{2} 26^{+} \mathrm{Iba1}^{+}\right.$: 96.10 cells $/ \mathrm{mm}^{2}$ in LPC vs. 1.95 cells $/ \mathrm{mm}^{2}$ in CTR, $p<0.001$; CD16/32 $2^{+} \mathrm{Iba1}^{+}: 45.43$ cells $/ \mathrm{mm}^{2}$ in LPC vs. 0 cells $/ \mathrm{mm}^{2}$ in CTR, $\left.p<0.001\right)$. In LPS mice, significant increases in the densities of $\mathrm{CD}^{206^{+}} \mathrm{Iba} 1^{+}$cells (221.00 cells $/ \mathrm{mm}^{2}$ in LPS vs. 3.32 cells $/ \mathrm{mm}^{2}$ in CTR, $p<$ 
$0.0001)$ and $\mathrm{CD} 16 / 32^{+} \mathrm{Iba1}^{+}$cells $\left(224.60\right.$ cells $/ \mathrm{mm}^{2}$ in LPS vs. 0 cells $/ \mathrm{mm}^{2}$ in CTR, $p<0.0001$ ) were observed dispersed within the dorsal column at $3 \mathrm{dpi}$. The density of CD206 ${ }^{+} \mathrm{Iba}^{+}{ }^{+}$cells was further increased $(270.20$ cells/ $\mathrm{mm}^{2}$ in LPS vs. 1.39 cells $/ \mathrm{mm}^{2}$ in CTR, $\left.p<0.0001\right)$ and concentrated within the demyelination area at $10 \mathrm{dpi}$, while $\mathrm{CD} 16 / 32^{+} \mathrm{Iba} 1^{+}$cells was significantly reduced compared to the early stage $\left(140.80\right.$ cells $/ \mathrm{mm}^{2}$ in LPS vs. 0 cells $/ \mathrm{mm}^{2}$ in CTR, $\left.p<0.0001\right)$. Densities of both $\mathrm{CD}^{206}{ }^{+} \mathrm{Iba1}^{+}$and $\mathrm{CD} 16 / 32^{+} \mathrm{Iba}^{+}$cells were markedly downregulated to the control levels at $21 \mathrm{dpi}$ $\left(\mathrm{CD}^{206}{ }^{+} \mathrm{Iba1}^{+}: 24.33\right.$ cells $/ \mathrm{mm}^{2}$ in LPS vs. 1.95 cells $/ \mathrm{mm}^{2}$ of CTR, $p>0.05$; CD16/32 $2^{+} \mathrm{Iba}^{+}: 21.69$ cells $/ \mathrm{mm}^{2}$ in LPS vs. 0 cells $/ \mathrm{mm}^{2}$ in CTR, $p>0.05$ ). The density of $\mathrm{CD}^{206^{+}} \mathrm{Iba}^{+}{ }^{+}$cells in LPS mice remained higher than that in LPC mice until the decrease at the late stage (3 dpi: 221.00 cells $/ \mathrm{mm}^{2}$ in LPS vs. 163.00 cells $/ \mathrm{mm}^{2}$ in LPC, $p<$ 0.05 ; $10 \mathrm{dpi}: 270.20$ cells $/ \mathrm{mm}^{2}$ in LPS vs. 244.70 cells $/ \mathrm{mm}^{2}$ in LPC, $p>0.05$; 21 dpi: 24.33 cells $/ \mathrm{mm}^{2}$ in LPS vs. 96.10 cells $/ \mathrm{mm}^{2}$ in LPC, $\left.p<0.01\right)$. The density of CD16/ $32^{+} \mathrm{Iba}^{+}$cells was higher than that in LPC mice at the early stage but was reduced and lower than LPC during the middle and late stages ( $3 \mathrm{dpi}: 224.60$ cells $/ \mathrm{mm}^{2}$ in LPS vs. 200.40 cells $/ \mathrm{mm}^{2}$ in LPC, $p<0.05 ; 10$ dpi: 140.80 cells/ $\mathrm{mm}^{2}$ in LPS vs. 344.20 cells $/ \mathrm{mm}^{2}$ in LPC, $p<0.0001 ; 21$ dpi: 21.69 cells $/ \mathrm{mm}^{2}$ in LPS vs. 45.43 cells $/ \mathrm{mm}^{2}$ in LPC, $p<0.05)$. The proportion of M1 and M2 phenotypes in $\mathrm{M} / \mathrm{M}$ were different comparing LPC and LPS mice along all time-points (Fig. 8e, f). There was no significant change in the proportions of $\mathrm{CD} 206^{+} \mathrm{Iba1}^{+}$and $\mathrm{CD} 16 / 32^{+} \mathrm{Iba1}^{+}$at the early and middle stages in the LPC-induced demyelination area (Fig. 8e). A substantial decrease was identified at $21 \mathrm{dpi}$ in the proportion of $\mathrm{CD} 16 / 32^{+} \mathrm{Iba} 1^{+}$, resulting in a dramatic decrease in the M1/M2 ratio during the late stage. In LPS mice, the M1/M2 ratio was similar to that in LPC mice at 3 dpi but dramatically dropped at 10 dpi due to reduced $\mathrm{CD} 16 / 32^{+} \mathrm{Iba}^{+}$cells and increased CD206 ${ }^{+} \mathrm{Iba}^{+}$cells (Fig. 8f).

Similar to the patterns of $\mathrm{CD}_{206} \mathrm{Iba}^{+}$cells and $\mathrm{CD} 16 / 32^{+} \mathrm{Iba}^{+}$cells, the densities of $\mathrm{Arg} 1^{+} \mathrm{Iba}^{+}$and $\mathrm{CD} 6^{+} \mathrm{Iba}^{+}$cells were significantly increased at $3 \mathrm{dpi}$ after LPC injection (Arg1 ${ }^{+} \mathrm{Iba1}: 214.50$ cells $/ \mathrm{mm}^{2}$ in LPC vs. 1.01 cells $/ \mathrm{mm}^{2}$ in CTR, $p<0.0001 ; \mathrm{CD}^{+} 6^{+} \mathrm{Iba1} 1^{+}$: 140.90 cells $/ \mathrm{mm}^{2}$ in LPC vs. 0.43 cells $/ \mathrm{mm}^{2}$ in CTR, $p<$ 0.0001 ), and both phenotypes were localized along the spared dorsal margins (Additional file 4: Figure S2 A-B). The $\mathrm{Arg} 1^{+} \mathrm{Iba}^{+}{ }^{+}$cells were restricted to the demyelination lesion core and surrounded by other $\mathrm{Iba}^{+}$cells like $\mathrm{CD} 86^{+} \mathrm{Iba1}^{+}$cells at $10 \mathrm{dpi}$, consistent with the localization of $\mathrm{CD} 206^{+} \mathrm{Iba}^{+}{ }^{+}$and $\mathrm{CD} 16 / 32^{+} \mathrm{Iba}^{+}$cells at 10 dpi (Fig. 8a, b). Densities of both $\mathrm{Arg} 1^{+} \mathrm{Iba} 1^{+}$and $\mathrm{CD}^{+} 6^{+} \mathrm{Iba1}^{+}$cells were greatly reduced at $21 \mathrm{dpi}$ (Arg1 $1^{+} \mathrm{Iba}^{+}: 26.71$ cells $/ \mathrm{mm}^{2}$ in LPC vs. 0.45 cells $/ \mathrm{mm}^{2}$ in CTR, $p>0.05$; $\mathrm{CD}^{+} 6^{+} \mathrm{Iba1}^{+}: 90.28$ cells $/ \mathrm{mm}^{2}$ in LPC vs. 1.73 cells $/ \mathrm{mm}^{2}$ in CTR, $p<0.0001$ ). In LPS mice, similar to those of $\mathrm{CD}_{206}{ }^{+} \mathrm{Iba}^{+}$and $\mathrm{CD} 16 / 32^{+} \mathrm{Iba} 1^{+}$ cells (Fig. 8a, b), Arg $1^{+} \mathrm{Iba} 1^{+}$and $\mathrm{CD} 86^{+} \mathrm{Iba} 1^{+}$cells were diffusely localized and increased from the early to middle stage and returned to the control levels during the late stage (Additional file 4: Figure S2 A-B). The density of $\operatorname{Arg} 1^{+} \mathrm{Iba} 1^{+}$cells in LPS mice was higher than that in LPC mice until the robust decrease at the late stage (3 dpi: 415.20 cells $/ \mathrm{mm}^{2}$ in LPS vs. 214.50 cells $/ \mathrm{mm}^{2}$ in LPC, $p<0.0001 ; 10$ dpi: 260.60 cells $/ \mathrm{mm}^{2}$ in LPS vs. 164.50 cells $/ \mathrm{mm}^{2}$ in LPC, $p<0.0001 ; 21$ dpi: 19.49 cells/ $\mathrm{mm}^{2}$ in LPS vs. 26.71 cells $/ \mathrm{mm}^{2}$ in LPC, $p>0.05$ ). The density of $\mathrm{CD}^{-} 6^{+} \mathrm{Iba} 1^{+}$cells in LPS mice was lower than that in LPC mice at all stages (3 dpi: 34.65 cells $/ \mathrm{mm}^{2}$ in LPS vs. 140.90 cells $/ \mathrm{mm}^{2}$ in LPC, $p<0.0001 ; 10$ dpi: 136.60 cells $/ \mathrm{mm}^{2}$ in LPS vs. 266.90 cells $/ \mathrm{mm}^{2}$ in LPC, $p<0.0001 ; 21 \mathrm{dpi}: 21.25$ cells $/ \mathrm{mm}^{2}$ in LPS vs. 90.28 cells $/ \mathrm{mm}^{2}$ in LPC, $p<0.0001$ ) (Additional file 4: Figure S2 C and D). These changes in $\mathrm{Arg}^{+} \mathrm{Iba1}^{+}$(M2) and $\mathrm{CD}^{2} 6^{+} \mathrm{Iba1}^{+}$(M1) cells were consistent with those in $\mathrm{CD}^{206}{ }^{+} \mathrm{Iba1}^{+}$(M2) and $\mathrm{CD} 16 / 32^{+} \mathrm{Iba1}^{+}$(M1) cells between LPC- and LPS-induced lesions.

The proportion of $\mathrm{CD} 86^{+} \mathrm{Iba}^{+}$cells remained at similar levels until the late stage with a mild decrease (LPC: 0.44 at $10 \mathrm{dpi}$ vs. 0.41 at $3 \mathrm{dpi}, p>0.05 ; 0.34$ at $21 \mathrm{dpi}$ vs. 0.44 at $10 \mathrm{dpi}, p<0.05)$. However, the proportion of Arg $1^{+} \mathrm{Iba}^{+}$cells progressively declined from 10 to 21 dpi (LPC: 0.26 at $10 \mathrm{dpi}$ vs. 0.54 at $3 \mathrm{dpi}, p<0.0001 ; 0.10$ at $21 \mathrm{dpi}$ vs. 0.26 at $10 \mathrm{dpi}, p<0.001$ ) in the LPC mice (Additional file 4: Figure S2 E). In LPS mice, although the proportion of $\mathrm{Arg}^{+}{ }^{+} \mathrm{Iba1}^{+}$cells progressively declined from 10 to $21 \mathrm{dpi}$, it still remained at relatively high levels during the middle stage (LPS: 0.66 at $10 \mathrm{dpi}$ vs. 0.76 at $3 \mathrm{dpi}, p<0.05 ; 0.11$ at $21 \mathrm{dpi}$ vs. 0.66 at $10 \mathrm{dpi}$, $p<0.0001)$. In contrast, the proportion of $\mathrm{CD}^{+} 6^{+} \mathrm{Iba}^{+}$ cells rapidly increased to a relatively low level at $3 \mathrm{dpi}$, then dramatically increased at $10 \mathrm{dpi}$ but returned to the early stage level at $21 \mathrm{dpi}$ (LPS: 0.34 at $10 \mathrm{dpi}$ vs. 0.07 at $3 \mathrm{dpi}, p<0.0001 ; 0.12$ at $21 \mathrm{dpi}$ vs. 0.34 at $10 \mathrm{dpi}, p<$ 0.0001 ) in the LPS mice (Additional file 4: Figure S2 F).

\section{Correlations between $\mathrm{M} / \mathrm{M}$ polarization, myelin integrity, and sensorimotor function}

To identify the interdependence of demyelination severity and changes in sensorimotor function, correlations were measured between mean OD ratio and mean balance beam score after LPC or LPS injection (Fig. 9a). The size of a correlation coefficient $(r)$ could be interpreted as very high positive or negative correlation $(0.90$ to 1.00 or -0.90 to -1.00 ), high positive or negative correlation ( 0.70 to 0.90 or -0.70 to -0.90$)$, moderate positive or negative correlation $(0.50$ to 0.70 or -0.50 to -0.70 ), low positive or negative correlation (0.30 to 0.50 or -0.30 to -0.50$)$, and little if any correlation (0.00 to 




0.30 or 0.00 to -0.30$)[53,54]$. A high positive correlation was found in the LPC group $(r=0.8791, p=$ 0.0211 ), while a similar positive correlation trend was observed in the LPS group but with no statistical significance $(r=0.7282, p=0.1008)$. Considering the distinct $\mathrm{M} / \mathrm{M}$ polarization patterns between LPC- and LPS- 
induced demyelination, correlations between OD ratio and M1 $\left(\mathrm{CD} 16 / 32^{+} \mathrm{Iba}^{+}\right.$or $\left.\mathrm{CD}^{+} 6^{+} \mathrm{Iba1}^{+}\right)$and $\mathrm{M} 2$ $\left(\mathrm{CD} 206^{+} \mathrm{Iba}^{+}\right.$or $\left.\mathrm{Arg}^{+} \mathrm{Iba}^{+}\right)$proportions were calculated in LPC and LPS groups, respectively (Fig. 9b, c). Significant negative correlation existed between OD ratio and $\mathrm{CD} 16 / 32^{+} \mathrm{Iba1}^{+}$(M1) or $\mathrm{Arg}^{+} \mathrm{Iba1}^{+}$(M2) proportion (very high in $\mathrm{CD} 16 / 32^{+} \mathrm{Ibal}^{+}: r=-0.9712, p<$ 0.0001; high in $\operatorname{Arg}^{+} \mathrm{Iba1}^{+}: r=-0.8041, p=0.0090$ ), while a moderate negative correlation existed between $\mathrm{OD}$ ratio and $\mathrm{CD} 6^{+} \mathrm{Iba1}^{+}$(M1) proportion $(r=-$ $0.6969, p=0.0369)$ in the LPC group. In contrast, high negative correlation was observed between OD ratio and $\mathrm{CD} 6^{+} \mathrm{Iba1}^{+}$(M1) or $\mathrm{CD}^{+} 06^{+} \mathrm{Iba1}^{+}$(M2) proportion $\left(\mathrm{CD}^{+} 6^{+} \mathrm{Iba1}^{+}: r=-0.8192, p=0.0069 ; \mathrm{CD}^{+} 06^{+} \mathrm{Iba1}^{+}: \mathrm{r}=\right.$ $-0.8549, p=0.0033$ ) in the LPS group.

\section{Discussion}

LPC- and LPS-induced focal demyelination mouse models in spinal white matter are widely used to investigate the cellular dynamic response during the demyelination-remyelination process. The LPC-induced demyelination lesion shows some features of the pattern I lesion (sharply demarcated lesion targeted on myelin; numerous oligodendrocytes reappear in central portion of the plaque) that occur in approximately $15 \%$ of biopsied MS patients [55], while the LPS model resembles the pattern III lesion (diffuse inflammatory demyelination) that is found in $26 \%$ of biopsied MS patients [26, $32,33]$. Although the temporal profile of these two focal MS models has been characterized [26, 29, 56], the dynamic response of glial cells during demyelination followed by spontaneous remyelination has not been clearly defined. In this study, we focused on the temporal and spatial features of $\mathrm{M} / \mathrm{M}$ activation/polarization and OPC response in LPC- and LPS-induced focal demyelination lesions. We found that LPC and LPS induce special lesion patterns (Additional file 5: Figure S3). The unique lesion patterns and balance beam function are tightly correlated to specific $\mathrm{M} / \mathrm{M}$ polarization probably due to different pathogenic mechanisms leading to demyelination.

LPC causes OL cell death and myelin loss followed by activation of secondary inflammation that may exaggerate the demyelination lesion. However, LPS initiates an inflammatory response that triggers the demyelination process. This difference in the pathological process between LPC and LPS is due to their distinct mechanisms leading to demyelination: LPC is a potent membranedissolving toxin while LPS activates inflammation via TLR-4 acting as an agonist [26, 29, 32]. Compared to the acute and intense lesion pattern elicited by LPC, the LPS-induced demyelination is progressive and relatively late (Fig. 2). Additional DTI imaging studies not only confirmed the temporal characteristics of the focal demyelination lesion by LFB staining but also proved a consistent and accurate in vivo imaging approach to monitor the progression of the demyelinationremyelination progress (Fig. 3). In accordance with the demyelination/histological patterns (OD ratio), balance beam performance showed similar temporal changes (Figs. 4 and 9a). This data indicated that fine sensorimotor function could be a sensitive assessment of demyelination in the dorsal columns of the spinal cord.

During the demyelination-remyelination process, a dynamic glial cell response occurs in the epicenter of the demyelination lesion, including activation of $\mathrm{M} / \mathrm{M}$ and astrocytes, recruitment of OPCs, OPC proliferation, and OL differentiation. In LPC-induced focal lesions, adult OPCs aggregated along the adjacent GM and margin of the lesion and dramatically proliferated at the early stage, which migrated into the lesion epicenter and differentiated to initiate remyelination during the middle stage (Fig. 5 and Additional file 3: Figure S1 A). Meanwhile, LPC-mediated glial activation (astrocytes and M/ $\mathrm{M})$ as well as proliferation started in the early stage and reached its peak level during the middle stage, corresponding to secondary inflammation induced after the toxin-induced direct demyelination (Figs. 5 and Additional file 3: Figure S1 B and C). The M2 (CD206 ${ }^{+}$and $\operatorname{Arg} 1^{+}$) was localized in the lesion epicenter with OPCs surrounded by M1 (CD16/32 $2^{+}$and $\left.\mathrm{CD} 86^{+}\right)$and activated astrocytes (Figs. 6 and 8 and Additional file 4: Figure S2). In contrast, OPCs, activated M/M (both $\mathrm{M} 1$ and M2), and astrocytes were distributed diffusely throughout the demyelination in the dorsal column WM and adjacent GM in LPS-induced lesions. OPC recruitment and glial activation dramatically increased at both early and middle stages but were significantly downregulated at the late stage (Figs. 5, 6, and 8, and Additional file 4: Figure S2).

Cytokines are a key link between the neuroinflammatory response and demyelination-remyelination process. The activated $\mathrm{M} / \mathrm{M}$ and astrocytes are primary sources of the production of pro- and anti-inflammatory factors [12, 26, 57]. Significant upregulation of monocyte-secreted TNFa is detected in patients with stable MS [58]. Both in vitro and in vivo experimental studies showed that excessive TNF $\alpha$ causes myelin swelling, oligodendrocyte necrosis, and demyelination $[59,60]$. Another pro-inflammatory cytokine IL-1 $\beta$ is also significantly released into the cerebrospinal fluid of MS patients in the active disease state [61], and higher levels are closely related to a more severe progression and poor prognosis of patients with a relapsingremitting MS $[62,63]$. Chronic expression of IL-1 $\beta$ in the rat striatum via adenovirus results in inflammatory toxicity and demyelination [62, 64]. As anti-inflammatory cytokines, TGF- $\beta 1$ is reduced in serum but increased in the cerebrospinal fluid in MS patients [65] and IGF-1 is detected in 

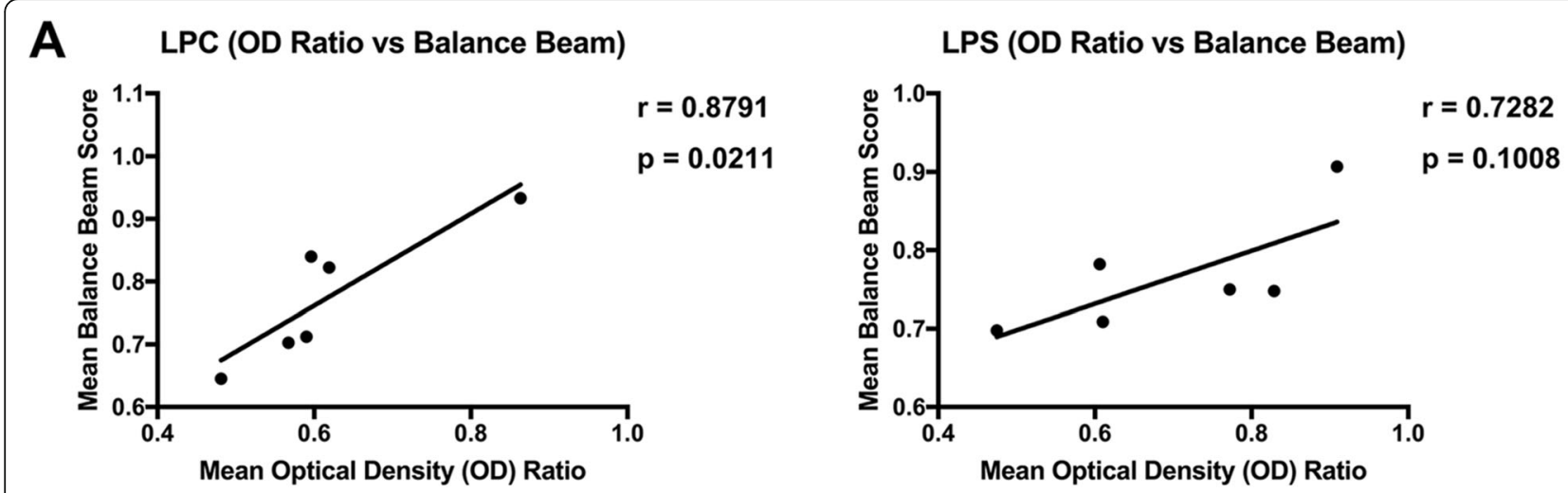

\section{B LPC (OD Ratio vs M/M Polarization)}

\section{LPC (OD Ratio vs M/M Polarization)}
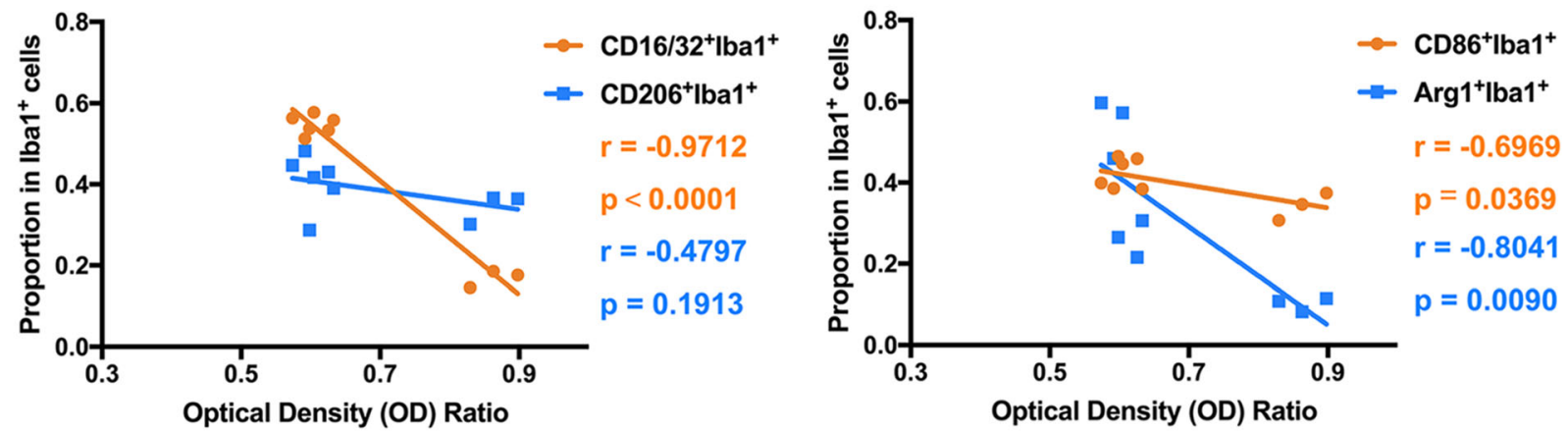

\section{LPS (OD Ratio vs M/M Polarization)}

\section{LPS (OD Ratio vs M/M Polarization)}
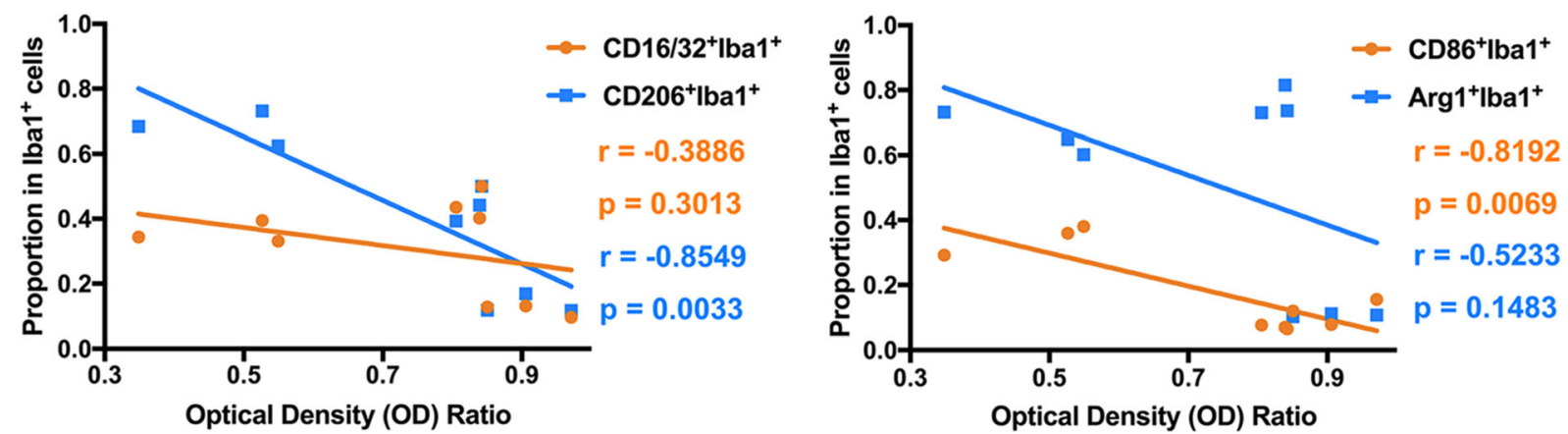

Fig. 9 Correlations between demyelination severity, sensorimotor function, and M/M polarization. a Positive correlation between demyelination severity (OD ratio) and sensorimotor function (balance beam) was statistically significant in the LPC group (left; $r=0.8791, p=0.0211$ ), but not in the LPS group (right; $r=0.7282, p=0.1008$ ). b Negative correlations between demyelination (OD ratio) severity and M/M polarization in the LPC group (Left: CD16/


Negative correlations between demyelination (OD ratio) severity and M/M polarization in the LPS group (Left: CD16/32 ${ }^{+} \mathrm{Iba1} 1^{+}, r=-0.3886, p=0.3013$;

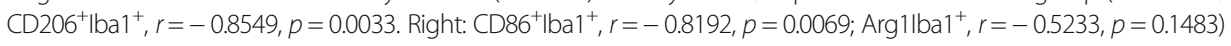

activated astrocytes in active MS lesions [66] even though the level of IGF-1 in serum and cerebrospinal fluid are not changed in MS patients [67]. Therapeutic application of TGF- $\beta 1$ or IGF- 1 in animals showed a neuroprotective role in demyelination by suppressing pro-inflammatory cytokines, supporting OL differentiation, and promoting remyelination [68-71]. In our study, dramatic increases in pro- inflammatory cytokines were identified in the early stage of the LPS model and middle stage of the LPC model, in correlation with their different timing in the inflammatory response and M/M activation level (Fig. 7). The production of anti-inflammatory cytokines has gradually increased, which might be induced by the pro-inflammatory molecules, corresponding to the increased polarization into M2 
and improved niche for the survival, recruitment, and differentiation of OPC/OL. The levels of pro-inflammatory cytokines like TNF $\alpha$ (from astrocytes and M/M $\left(\mathrm{CD}^{+} 6^{+}\right)$) and IL-1 $\beta$ (only from $\mathrm{M} / \mathrm{M}\left(\mathrm{CD}^{+} 6^{+}\right)$) [72] are increased in cerebrospinal fluid and serum of MS patients, with a positive correlation with disease severity [73, 74]. Despite the damaging effect of OL cell death and axonal degeneration $[75,76]$, pro-inflammatory cytokines may be beneficial for remyelination. TNF $\alpha$ and IL- $1 \beta$ promote the astrocytic synthesis of neurotrophic/growth factors like neurotrophins and ciliary neurotrophic factor, resulting in the improved survival and differentiation of OPC/OL [76-81]. TNF $\alpha$ is reported to improve OPC proliferation and remyelination via tumor necrosis factor receptor 2 (TNFR2) activation [73, 81], which might be related to an increased expression of chemokine C$\mathrm{X}-\mathrm{C}$ motif chemokine ligand 12 (CXCL12) from astrocytes [73]. IL-1 $\beta$ promotes remyelination by enhancing the mobilization of adult OPCs [82]. Moreover, IL-1 $\beta$ is found to induce the production of anti-inflammatory cytokine IGF-1, presumably from both activated M/M $\left(\mathrm{CD} 206^{+}\right.$or $\left.\operatorname{Arg}^{+}\right)$and astrocytes, which promotes the accumulation and differentiation of OPCs and protects OL from cell death $[83,84]$. Another important antiinflammatory cytokine, TGF- $\beta 1$, is released from activated $\mathrm{M} / \mathrm{M}\left(\mathrm{CD}^{2} 06^{+}\right.$or $\left.\mathrm{Arg} 1^{+}\right)$and this signaling is accentuated by pro-inflammatory molecules to deactivate $\mathrm{M} / \mathrm{M}$ activation and drive $\mathrm{M} / \mathrm{M}$ polarization into $\mathrm{M} 2$ in combination with other anti-inflammatory cytokines (IL4 and IL10) [85-88]. It is noteworthy that the roles of these cytokines during the pathological process are interregulated, and the balance is dynamic and delicate. Therefore, it is crucial to boost the correct $\mathrm{M} / \mathrm{M}$ phenotype at the right time with consideration of the dynamic balance of cytokines.

It has long been debated whether $\mathrm{M} / \mathrm{M}$ activation is detrimental or beneficial in MS. M/M is a central player in surveillance and neuroinflammation [12, 57]. Focal accumulation of $\mathrm{M} / \mathrm{M}$ is found at the sites of active demyelination and neurodegeneration [89-92]. Moreover, $\mathrm{M} / \mathrm{M}$ in active MS lose homeostatic status and display M1 characteristics or an intermediate activation status, and restoration of $\mathrm{M} / \mathrm{M}$ status is related to disease inactivity $[89,93]$. The accumulation of $\mathrm{M} / \mathrm{M}$ and the timing of $\mathrm{M} / \mathrm{M}$ polarization affect the efficiency of remyelination, which might be related to the regulation of the OPC/OL response via the production of inflammation-relevant cytokines and growth/trophic factors $[14,16,57,77]$. Our findings indicate that LPC- and LPSinduced demyelination models adopt different patterns of localization/timing of $\mathrm{M} / \mathrm{M}$ activation and $\mathrm{M} / \mathrm{M}$ polarization (Figs. 6, 8, and 9, and Additional file 4: Figure S2). In addition, different temporal OPC/OL responses during recruitment and differentiation may explain the different magnitudes of lesion severity and duration of the demyelination- remyelination process between LPC- and LPS-induced lesions (Fig. 5). A time lag of 7-10 days was observed in the demyelination LPS group and the M/M activation/M1-relevant pro-inflammatory cytokines (Fig. 7a, b) in the LPC group. These distinct time courses may be explained by the different timing of demyelination and inflammation between the LPC and LPS groups. Notably, the M1/M2-dominant phenotype was observed at the middle stage in the LPC lesions, while the M2/M1-dominant phenotype occurred at the early and middle stages in LPS lesions (Fig. 8 and Additional file 4: Figure S2). Both M1 and M2 play major roles in the LPC- and LPS-induced demyelination-remyelination process. However, specific profiles of $\mathrm{M} / \mathrm{M}$ polarization are tightly correlated to the pathogenic mechanism leading to demyelination (Fig. 9b, c). A unique spatial change was identified in phenotype localization in the LPC group at $10 \mathrm{dpi}$ (the timing for initial remyelination). The M2 phenotype was concentrated within the demyelination lesion core, surrounded by OPC/OL, astrocytes, and M1 phenotype. This regional arrangement suggests that, besides the polarization phenotype, the spatial change of M1 (outside; surveillance, barrier, pro-inflammation) and M2 (inside; regeneration, protection, anti-inflammation) could be another essential factor for OPC differentiation and initial remyelination. Although M1 is generally considered detrimental due to its roles in pro-inflammation, the findings in the phenotype spatial and temporal alternations, the relevant secreted cytokines, and the response of $\mathrm{OPC} / \mathrm{OL}$ suggest that both M1 and M2 are critical to efficient remyelination. The balance and timing of $\mathrm{M} / \mathrm{M}$ localization and polarization play essential roles in remodeling OPC behavior and the demyelination-remyelination process.

Of note, only female mice were used in the current study. MS is a sexually dimorphic disease with a female-to-male ratio as high as 3:1 [94, 95]. Sex-dependent differences in incidence, progression, and responses are reported in MS patients [96, 97] and experimental autoimmune encephalomyelitis rodent models $[98,99]$. Female mice are more vulnerable to demyelination, which may be related to the shorter oligodendrocyte lifespan and higher myelin protein turnover [100]. Females are more easily to develop severe demyelination with stronger innate and adaptive immune responses, including greater $\mathrm{M} / \mathrm{M}$ activation and phagocytic capacity, pro-inflammatory cytokine responses, and $\mathrm{T}$ cell proliferation and antibody responses [101]. The density of oligodendrocytes and myelin gene expression in male mice are greater than female mice $[100,102]$, which make them less vulnerable to demyelination insults. However, male mice have a higher expression of TLR-4 on $M / M$, which might mediate LPS to trigger severe inflammatory responses with more pro-inflammatory cytokine production $[101,103]$. Detailed sexual dimorphism in glial and inflammatory responses are worthy of further investigation during the demyelination-remyelinaiton process. 


\section{Conclusions}

LPC and LPS induce distinctive temporal and spatial demyelination patterns: LPS produces diffuse demyelination lesions, and its peak of demyelination and functional decline occurs later than LPC. OPC/OL, astrocytes, and $\mathrm{M} / \mathrm{M}$ are scattered throughout the LPS-induced demyelination lesions but are distributed in a layer-like pattern in the LPC-induced lesions. The specific M/M polarization is tightly correlated to specific pathology and sensorimotor function probably caused by different pathogenic mechanisms that leads to demyelination. The differences in $\mathrm{M} /$ $\mathrm{M}$ subpopulations and its localization are closely associated with the demyelination type and timing, reflecting the complex roles of $\mathrm{M} / \mathrm{M}$ during the demyelinationremyelination process. The inflammatory response is a key feature of MS and a promising therapeutic target. These findings provide a fundamental knowledge on the pathological glial response in different types of demyelination lesions. These findings will benefit the strategic development in promoting/inhibiting certain inflammatory phenotypes at the appropriate time.

\section{Supplementary information}

Supplementary information accompanies this paper at https://doi.org/10. 1186/s12974-019-1586-1.

Additional file 1: Table S1. Antibodies for Immunohistochemistry.

Additional file 2: Table S2. TaqMan Gene Expression Assays (FAM Dye/ MGB probe) for Real-time qRT-PCR.

Additional file 3: Figure S1. Temporal characteristics of glial cell proliferation following dorsal demyelination. (A-C) Representative photomicrographs of proliferative (A) OPCs (Pdgfra ${ }^{+} \mathrm{Ki} 67^{+}$), (B) M/M $\left(\mathrm{baa} 1^{+} \mathrm{Ki} 67^{+}\right)$, and $(\mathrm{C})$ astrocytes $\left(\mathrm{GFAP}^{+} \mathrm{Ki} 67^{+}\right)$in the dorsal demyelination area in the CTR, LPC, and LPS groups at 3, 10, and $21 \mathrm{dpi}$. Dashed white line indicates the margins of the dorsal columns. Representative double labelling is indicated by arrowhead and single labelling is indicated by arrow in the inset for better view. Scale bar, $50 \mu \mathrm{m}$ for panel figure; $20 \mu \mathrm{m}$ for inset. (D-F) Quantification of the cell density of proliferative (D) OPCs (Pdgfra ${ }^{+} \mathrm{Ki} 67^{+}$cells $\left./ \mathrm{mm}^{2}\right)$, (E) M/M (Iba ${ }^{+} \mathrm{Ki} 67^{+}$cells $/ \mathrm{mm}^{2}$ ), and (F) astrocytes (GFAP ${ }^{+} \mathrm{Ki}^{+}$cells $/ \mathrm{mm}^{2}$ ) within the dorsal column lesion site in the three groups at 3,10, and $21 \mathrm{dpi}$. Cell densities was compared to the CTR group $\left.{ }^{* *} p<0.01,{ }^{* * *} p<0.001,{ }^{* * * *} p<0.0001\right)$ and the LPC group $(\times p<0.05, \times \times \times p<0.001, \times \times \times \times p<0.0001)$ at each given time-point; for each group, cell density was compared to $3 \mathrm{dpi}$ (\#\# $p<0.01$, \#\#\# $p<$ 0.001 , \#\#\#\# $p<0.0001)$ and $10 \mathrm{dpi}(+++p<0.001,++++p<0.0001)$. (G, H) Proportions of proliferative OPCs $\left(\mathrm{Pdgfra}^{+} \mathrm{Ki} 67^{+}\right), \mathrm{M} / \mathrm{M}\left(\mathrm{Iba} 1^{+} \mathrm{Ki} 67^{+}\right)$, and astrocytes $\left(\mathrm{GFAP}^{+} \mathrm{Ki} 67^{+}\right)$in total proliferative cells $\left(\mathrm{Ki} 67^{+}\right)$within the dorsal column at the lesion site in $(G)$ LPC and $(H)$ LPS groups at 3, 10, and 21 dpi. The cell proportion was compared to $3 \mathrm{dpi}$ (\# $p<0.05$, \#\# $p<0.01$, \#\#\#\# $p<0.0001)$ and $10 \mathrm{dpi}(++p<0.01,++++p<0.0001)$ for each group. Data were collected from three animals per group at each timepoint ( $n=3$ mice)

Additional file 4: Figure S2. Temporal characteristics of M/M polarization and localization ( $\mathrm{Arg} 1^{+} \mathrm{|ba} 1^{+}$and $\left(\mathrm{CD} 86^{+} \mathrm{|ba} 1^{+}\right.$) following dorsal demyelination models. (A, B) Representative photomicrographs of (A) $\mathrm{M} 2\left(\mathrm{Arg}^{+} \mid \mathrm{ba} 1^{+}\right)$and (B) $\mathrm{M} 1\left(\mathrm{CD} 86^{+} \mid \mathrm{ba} 1^{+}\right)$at the dorsal demyelination area in the CTR, LPC, and LPS groups at 3, 10, and $21 \mathrm{dpi}$. Dashed white line indicates the margins of the dorsal columns. Representative double labelling is indicated by arrowhead and single labelling is indicated by arrow in the inset for better view. Scale bar, $50 \mu \mathrm{m}$ for panel figure; $20 \mu \mathrm{m}$ for inset. (C, D) Quantification of cell densities of (C) M2 $\left(\right.$ Arg $1^{+} \mid \mathrm{ba} 1^{+}$cells $\left./ \mathrm{mm}^{2}\right)$ and (D) M1 $\left(\mathrm{CD}^{2} 6^{+} \mathrm{Iba} 1^{+}\right.$cells $\left./ \mathrm{mm}^{2}\right)$ within the dorsal columns at the lesion site in the three groups at 3, 10, and $21 \mathrm{dpi}$. Cell density was compared to the CTR group ( ${ }^{*} p<0.05$, $\left.{ }^{* * * *} p<0.0001\right)$ and the LPC group $(\times \times \times \times p<0.0001)$ at each given time-point; for each group, cell density was compared to $3 \mathrm{dpi}$ (\#\# $p<0.01$, \#\#\#\# $p<0.0001$ ) and $10 \mathrm{dpi}(++++p<0.0001)$. (E, F) Summary of the proportion of $M 2$

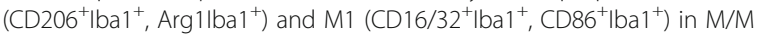
$\left(\mathrm{Iba} 1^{+}\right)$within the dorsal columns at the lesion site in (E) LPC and (F) LPS demyelination models at 3, 10, and $21 \mathrm{dpi}$. The cell proportion was compared to $3 \mathrm{dpi}(\# p<0.05$, \#\#\#\# $p<0.0001)$ and $10 \mathrm{dpi}(+p<0.05$, +++ $p<0.001,++++p<0.0001)$ for each group. Data were collected from three animals per group at each time-point ( $n=3$ mice).

Additional file 5: Figure S3. Graphic summary of LPC- and LPS-induced distinctive temporal and spatial demyelination patterns. In contrast to LPC-induced robust demyelination with a lag in inflammation/glial response, LPS stimulated strong inflammation/glial response from the early stage and produced diffuse demyelination lesions with its peak demyelination and functional decline later than LPC. OPC/OL, astrocytes, and M/M were scattered throughout the LPS-induced demyelination lesion, but were distributed in a layer-like pattern in the LPC-induced lesion. OPCs populated and migrated into the lesion center to differentiate into mature OLs: OPC/OL were distributed dispersedly in the LPS-induced lesion; while in LPC-induced lesion, OPC/OL were localized in layers around M2. At the late stage, both LPC- and LPS- produced demyelination reached spontaneous remyelination with the restoration of inflammatory niche, a change in M/M subpopulations, and the recruitment/differentiation of $\mathrm{OPC} / \mathrm{OL}$ into the lesion center. Specific M1/M2 polarization was closely associated with the demyelination-remyelination process, which might be related to the different mechanisms of LPC and LPS in causing inflammation and demyelination.

\section{Abbreviations}

AD: Axial diffusivity; ANOVA: Analysis of variance; Arg1: Arginase 1; CC1: Antiadenomatous polyposis coli clone; CD: Cluster of differentiation; CNS: Central nervous system; CTR: Control; CXCL12: C-X-C motif chemokine ligand 12; dpi: Days post-injection; DTI: Diffusion tensor imaging; FA: Fractional anisotropy; GFAP: Glial fibrillary acidic protein; GST-п: Glutathione STransferase Pi; Iba1: Ionized calcium binding adaptor molecule 1; IGF1: Insulin-like growth factor-1; IL-1 $\beta$ : Interleukin-1 beta; IOD: Integrated optical density; LFB: Luxol fast blue; LPC: L-a-Lysophosphatidylcholine; LPS: Lipopolysaccharide; M/M: Microglia/macrophages; MD: Mean diffusivity; MRI: Magnetic resonance imaging; MS: Multiple sclerosis; OD: Optical density; OL: Oligodendrocytes; Olig2: Oligodendrocyte Transcription Factor 2; OPC: Oligodendrocyte progenitor cell; PBS: Phosphate-buffered saline; Pdgfra: Platelet-derived growth factor receptor alpha; qRT-PCR: Real-time quantitative reverse transcription polymerase chain reaction; RD: Radial diffusivity; RNA: Ribonucleic acid; ROI: Region of interest; SD: Standard deviation; TGF- 31 : Transforming growth factor-beta 1; TLR: Toll-like receptor; TNFR2: Tumor necrosis factor receptor 2; TNFa: Tumor necrosis factor alpha; WM: White matter

\section{Acknowledgements}

Not applicable.

\section{Authors' contributions}

$\mathrm{TC}, \mathrm{CS}$, and JC conceived of the overall project and experimental designs. TC and JC acquired all the study data. YPZ, TC, and ZT performed the surgical procedures and postoperative care. $\mathrm{TC}, \mathrm{ZT}$, and $\mathrm{CY}$ conducted behavioral assessments. TC and MZ performed DTI imaging analyses. TC performed all tissue processing, histological staining, and qRT-PCR. TC, MK, and JC performed statistical analyses, TC and JC interpreted the data and drafted the manuscript. LS, GB, and CS participated in data interpretation and manuscript revision. All authors read and approved the final manuscript.

\section{Funding}

This work was partially supported by grants from the National Institute Of Neurological Disorders And Stroke of the National Institutes of Health (R21 NS098170, JC and CS), Kentucky Spinal Cord and Head Injury Research Trust (16-3A, JC and CS), and the NeuroCures Foundation, Inc. (JC). 


\section{Availability of data and materials}

The datasets generated and/or analyzed in the current study are available from the corresponding author on reasonable request.

\section{Ethics approval and consent to participate}

All surgical procedures and postoperative care were performed under the approval of the University of Louisville Animal Care and Use Committee.

\section{Consent for publication}

Not applicable.

\section{Competing interests}

The authors declare that they have no competing interests.

\section{Author details}

'Department of Pediatrics, Pediatric Research Institute, University of Louisville School of Medicine, Donald Baxter Building, Suite 321B, 570 S. Preston Street, Louisville, KY 40202, USA. ${ }^{2}$ Norton Neuroscience Institute, Norton Healthcare, 210 East Gray Street, Suite 1102, Louisville, KY 40202, USA. ${ }^{3}$ Department of Orthopedics, China-Japan Union Hospital of Jilin University, Changchun 130033, People's Republic of China. ${ }^{4}$ Department of Pediatrics, The Second Affiliated Hospital and Yuying Children's Hospital of Wenzhou Medical University, Wenzhou 325027, People's Republic of China. ${ }^{5}$ Department of Radiology, University of Louisville School of Medicine, Louisville, KY 40202, USA. ${ }^{6}$ Department of Bioinformatics and Biostatistics, University of Louisville School of Public Health and Information Sciences, Louisville, KY 40202, USA. ${ }^{7}$ Department of Neurology, University of Louisville School of Medicine, Louisville, KY 40202, USA. ${ }^{8}$ Department of Pharmacology and Toxicology, University of Louisville, Louisville, KY 40202, USA. ${ }^{9}$ Department of Neurological Surgery, University of Louisville School of Medicine, Louisville, KY 40202, USA.

Received: 22 May 2019 Accepted: 11 September 2019 Published online: 17 October 2019

\section{References}

1. Franklin RJ, Ffrench-Constant C. Remyelination in the CNS: from biology to therapy. Nat Rev Neurosci. 2008;9:839-55.

2. Smith KJ, Blakemore WF, McDonald WI. Central remyelination restores secure conduction. Nature. 1979;280:395-6.

3. Funfschilling U, Supplie LM, Mahad D, Boretius S, Saab AS, Edgar J, et al. Glycolytic oligodendrocytes maintain myelin and long-term axonal integrity. Nature. 2012:485:517-21.

4. Patani R, Balaratnam M, Vora A, Reynolds R. Remyelination can be extensive in multiple sclerosis despite a long disease course. Neuropathol Appl Neurobiol. 2007;33:277-87.

5. Boyd A, Zhang H, Williams A. Insufficient OPC migration into demyelinated lesions is a cause of poor remyelination in MS and mouse models. Acta Neuropathol. 2013:125:841-59.

6. Patrikios P, Stadelmann C, Kutzelnigg A, Rauschka H, Schmidbauer M, Laursen $\mathrm{H}$, et al. Remyelination is extensive in a subset of multiple sclerosis patients. Brain. 2006;129:3165-72.

7. Raine CS, Wu E. Multiple sclerosis: remyelination in acute lesions. J Neuropathol Exp Neurol. 1993;52:199-204

8. Prineas JW, Barnard RO, Kwon EE, Sharer LR, Cho ES. Multiple sclerosis: remyelination of nascent lesions. Ann Neurol. 1993;33:137-51.

9. Chang A, Tourtellotte WW, Rudick R, Trapp BD. Premyelinating oligodendrocytes in chronic lesions of multiple sclerosis. N Engl J Med. 2002;346:165-73.

10. Lucchinetti C, Bruck W, Parisi J, Scheithauer B, Rodriguez M, Lassmann H. A quantitative analysis of oligodendrocytes in multiple sclerosis lesions. A study of 113 cases. Brain. 1999;122(Pt 12):2279-95.

11. Nataf S. Neuroinflammation responses and neurodegeneration in multiple sclerosis. Rev Neurol (Paris). 2009;165:1023-8.

12. DiSabato DJ, Quan N, Godbout JP. Neuroinflammation: the devil is in the details. J Neurochem. 2016;139(Suppl 2):136-53.

13. Cash $E$, Zhang $Y$, Rott $O$. Microglia present myelin antigens to $T$ cells after phagocytosis of oligodendrocytes. Cell Immunol. 1993;147:129-38.

14. Kotter MR, Zhao C, van Rooijen N, Franklin RJ. Macrophage-depletion induced impairment of experimental CNS remyelination is associated with a reduced oligodendrocyte progenitor cell response and altered growth factor expression. Neurobiol Dis. 2005;18:166-75.

15. Olah M, Amor S, Brouwer N, Vinet J, Eggen B, Biber K, et al. Identification of a microglia phenotype supportive of remyelination. Glia. 2012;60:306-21.

16. Miron VE, Boyd A, Zhao JW, Yuen TJ, Ruckh JM, Shadrach JL, et al. M2 microglia and macrophages drive oligodendrocyte differentiation during CNS remyelination. Nat Neurosci. 2013;16:1211-8.

17. Li WW, Setzu A, Zhao C, Franklin RJ. Minocycline-mediated inhibition of microglia activation impairs oligodendrocyte progenitor cell responses and remyelination in a non-immune model of demyelination. J Neuroimmunol. 2005;158:58-66.

18. Rodriguez M. Effectors of demyelination and remyelination in the CNS: implications for multiple sclerosis. Brain Pathol. 2007;17:219-29.

19. Foote AK, Blakemore WF. Inflammation stimulates remyelination in areas of chronic demyelination. Brain. 2005;128:528-39.

20. Huitinga I, van Rooijen N, de Groot CJ, Uitdehaag BM, Dijkstra CD. Suppression of experimental allergic encephalomyelitis in Lewis rats after elimination of macrophages. J Exp Med. 1990;172:1025-33.

21. Brosnan CF, Bornstein MB, Bloom BR. The effects of macrophage depletion on the clinical and pathologic expression of experimental allergic encephalomyelitis. J Immunol. 1981;126:614-20.

22. Edwards JP, Zhang X, Frauwirth KA, Mosser DM. Biochemical and functional characterization of three activated macrophage populations. J Leukoc Biol. 2006;80:1298-307

23. Miller RH, Fyffe-Maricich S, Caprariello AC. Animal models for the study of multiple sclerosis. In: Conn PM, editor. Animal models for the study of human disease. 2nd ed; 2017. p. 967-88.

24. Zhang Y, Zhang YP, Pepinsky B, Huang G, Shields LB, Shields CB, et al. Inhibition of LINGO-1 promotes functional recovery after experimental spinal cord demyelination. Exp Neurol. 2015;266:68-73.

25. Gu Z, Li F, Zhang YP, Shields LB, Hu X, Zheng Y, et al. Apolipoprotein E mimetic promotes functional and histological recovery in lysolecithininduced spinal cord demyelination in mice. J Neurol Neurophysiol. 2013:2014:10.

26. Felts PA, Woolston AM, Fernando HB, Asquith S, Gregson NA, Mizzi OJ, et al. Inflammation and primary demyelination induced by the intraspinal injection of lipopolysaccharide. Brain. 2005;128:1649-66.

27. Blakemore WF, Franklin RJ. Remyelination in experimental models of toxininduced demyelination. Curr Top Microbiol Immunol. 2008;318:193-212.

28. Hall SM. The effect of injections of lysophosphatidyl choline into white matter of the adult mouse spinal cord. J Cell Sci. 1972;10:535-46.

29. Jeffery ND, Blakemore WF. Remyelination of mouse spinal cord axons demyelinated by local injection of lysolecithin. J Neurocytol. 1995;24:775-81.

30. Fancy SP, Baranzini SE, Zhao C, Yuk DI, Irvine KA, Kaing S, et al. Dysregulation of the Wnt pathway inhibits timely myelination and remyelination in the mammalian CNS. Genes Dev. 2009;23:1571-85.

31. Lau LW, Keough MB, Haylock-Jacobs S, Cua R, Doring A, Sloka S, et al. Chondroitin sulfate proteoglycans in demyelinated lesions impair remyelination. Ann Neurol. 2012;72:419-32.

32. Desai RA, Davies AL, Tachrount M, Kasti M, Laulund F, Golay X, et al. Cause and prevention of demyelination in a model multiple sclerosis lesion. Ann Neurol. 2016;79:591-604.

33. Marik C, Felts PA, Bauer J, Lassmann H, Smith KJ. Lesion genesis in a subset of patients with multiple sclerosis: a role for innate immunity? Brain. 2007; 130:2800-15.

34. Wang Y, Gao Z, Zhang Y, Feng S-Q, Liu Y, Shields LBE, et al. Attenuated reactive gliosis and enhanced functional recovery following spinal cord injury in null mutant mice of platelet-activating factor receptor. Mol Neurobiol. 2015;53:3448-61.

35. Cai J, Zhu Q, Zheng K, Li H, Qi Y, Cao Q, et al. Co-localization of Nkx6.2 and $\mathrm{Nkx2.2}$ homeodomain proteins in differentiated myelinating oligodendrocytes. Glia. 2010;58:458-68.

36. Cai J, Qi Y, Hu X, Tan M, Liu Z, Zhang J, et al. Generation of oligodendrocyte precursor cells from mouse dorsal spinal cord independent of Nkx6 regulation and Shh signaling. Neuron. 2005:45:41-53.

37. Chu T, Zhou H, Wang T, Lu L, Li F, Liu B, et al. In vitro characteristics of valproic acid and all-trans-retinoic acid and their combined use in promoting neuronal differentiation while suppressing astrocytic differentiation in neural stem cells. Brain Res. 2015;1596:31-47.

38. Schmittgen TD, Livak KJ. Analyzing real-time PCR data by the comparative C(T) method. Nat Protoc. 2008;3:1101-8. 
39. Kozlowski P, Raj D, Liu J, Lam C, Yung AC, Tetzlaff W. Characterizing white matter damage in rat spinal cord with quantitative MRI and histology. J Neurotrauma. 2008;25:653-76.

40. Aung WY, Mar S, Benzinger TL. Diffusion tensor MRI as a biomarker in axonal and myelin damage. Imaging Med. 2013;5:427-40.

41. Concha L. A macroscopic view of microstructure: using diffusion-weighted images to infer damage, repair, and plasticity of white matter. Neuroscience. 2014;276:14-28.

42. Kim JH, Song S-K. Diffusion tensor imaging of the mouse brainstem and cervical spinal cord. Nat Protoc. 2013;8:409-17.

43. Ansari MK, Yong HY, Metz L, Yong WW, Zhang Y. Changes in tissue directionality reflect differences in myelin content after demyelination in mice spinal cords. J Struct Biol. 2014;188:116-22.

44. Wang G, Zhang YP, Gao Z, Shields LBE, Li F, Chu T, et al. Pathophysiological and behavioral deficits in developing mice following rotational accelerationdeceleration traumatic brain injury. Dis Model Mech. 2018;11:dmm030387.

45. Stanley JL, Lincoln RJ, Brown TA, McDonald LM, Dawson GR, Reynolds DS. The mouse beam walking assay offers improved sensitivity over the mouse rotarod in determining motor coordination deficits induced by benzodiazepines. J Psychopharmacol. 2005;19:221-7.

46. Boehm SL 2nd, Schafer GL, Phillips TJ, Browman KE, Crabbe JC. Sensitivity to ethanol-induced motor incoordination in 5-HT (1B) receptor null mutant mice is task-dependent: implications for behavioral assessment of genetically altered mice. Behav Neurosci. 2000;114:401-9.

47. Piot-Grosjean O, Wahl F, Gobbo O, Stutzmann JM. Assessment of sensorimotor and cognitive deficits induced by a moderate traumatic injury in the right parietal cortex of the rat. Neurobiol Dis. 2001;8:1082-93.

48. Carter RJ, Morton J, Dunnett SB. Motor coordination and balance in rodents. Curr Protoc Neurosci. 2001;15:8.12.1-8.4.

49. Luong TN, Carlisle HJ, Southwell A, Patterson PH. Assessment of motor balance and coordination in mice using the balance beam. J Vis Exp. 2011; 49:e2376.

50. Arfanakis K, Haughton VM, Carew JD, Rogers BP, Dempsey RJ, Meyerand ME. Diffusion tensor MR imaging in diffuse axonal injury. AJNR Am J Neuroradiol. 2002;23:794-802.

51. Beaulieu C, Does MD, Snyder RE, Allen PS. Changes in water diffusion due to Wallerian degeneration in peripheral nerve. Magn Reson Med. 1996;36:627-31.

52. Dijkhuizen RM, de Graaf RA, Tulleken KA, Nicolay K. Changes in the diffusion of water and intracellular metabolites after excitotoxic injury and global ischemia in neonatal rat brain. J Cereb Blood Flow Metab. 1999:19:341-9.

53. Hinkle DE, Wiersma W, Jurs SG. Applied statistics for the behavioral sciences. 5th ed. Boston: Houghton Mifflin; 2003.

54. Mukaka MM. Statistics corner: a guide to appropriate use of correlation coefficient in medical research. Malawi Med J. 2012;24:69-71.

55. Popescu BF, Pirko I, Lucchinetti CF. Pathology of multiple sclerosis: where do we stand? Continuum (Minneap Minn). 2013;19:901-21.

56. Crawford $\mathrm{AH}$, Chambers $\mathrm{C}$, Franklin RJ. Remyelination: the true regeneration of the central nervous system. J Comp Pathol. 2013;149:242-54.

57. Lloyd AF, Miron VE. Cellular and molecular mechanisms underpinning macrophage activation during remyelination. Front Cell Dev Biol. 2016;4:60.

58. Rudick RA, Ransohoff RM. Cytokine secretion by multiple sclerosis monocytes. Relationship to disease activity. Arch Neurol. 1992;49:265-70.

59. Payne SC, Bartlett CA, Harvey AR, Dunlop SA, Fitzgerald M. Myelin sheath decompaction, axon swelling, and functional loss during chronic secondary degeneration in rat optic nerve. Invest Ophthalmol Vis Sci. 2012;53:6093-101.

60. Selmaj KW, Raine CS. Tumor necrosis factor mediates myelin and oligodendrocyte damage in vitro. Ann Neurol. 1988;23:339-46.

61. Rossi S, Furlan R, De Chiara V, Motta C, Studer V, Mori F, et al. Interleukin1 beta causes synaptic hyperexcitability in multiple sclerosis. Ann Neurol. 2012;71:76-83.

62. Ferrari CC, Pott Godoy MC, Tarelli R, Chertoff M, Depino AM, Pitossi FJ. Progressive neurodegeneration and motor disabilities induced by chronic expression of IL-1 beta in the substantia nigra. Neurobiol Dis. 2006;24:183-93.

63. Rossi S, Studer V, Motta C, Germani G, Macchiarulo G, Buttari F, et al. Cerebrospinal fluid detection of interleukin-1 beta in phase of remission predicts disease progression in multiple sclerosis. J Neuroinflammation. 2014;11:32.

64. Ferrari CC, Depino AM, Prada F, Muraro N, Campbell S, Podhajcer O, et al. Reversible demyelination, blood-brain barrier breakdown, and pronounced neutrophil recruitment induced by chronic IL-1 expression in the brain. Am J Pathol. 2004;165:1827-37.
65. Rollnik JD, Sindern E, Schweppe C, Malin JP. Biologically active TGF-beta 1 is increased in cerebrospinal fluid while it is reduced in serum in multiple sclerosis patients. Acta Neurol Scand. 1997;96:101-5.

66. Gveric D, Cuzner ML, Newcombe J. Insulin-like growth factors and binding proteins in multiple sclerosis plaques. Neuropathol Appl Neurobiol. 1999:25:215-25.

67. Wilczak N, Schaaf M, Bredewold R, Streefland C, Teelken A, De Keyser J. Insulin-like growth factor system in serum and cerebrospinal fluid in patients with multiple sclerosis. Neurosci Lett. 1998;257:168-70.

68. Dobolyi A, Vincze C, Pal G, Lovas G. The neuroprotective functions of transforming growth factor beta proteins. Int J Mol Sci. 2012;13:8219-58.

69. McKinnon RD, Piras G, Ida JA Jr, Dubois-Dalca M. A role for TGF-beta in oligodendrocyte differentiation. J Cell Biol. 1993;121:1397-407.

70. Liu X, Yao DL, Webster H. Insulin-like growth factor I treatment reduces clinical deficits and lesion severity in acute demyelinating experimental autoimmune encephalomyelitis. Mult Scler. 1995;1:2-9.

71. Yao DL, Liu X, Hudson LD, Webster HD. Insulin-like growth factor I treatment reduces demyelination and up-regulates gene expression of myelin-related proteins in experimental autoimmune encephalomyelitis. Proc Natl Acad Sci U S A. 1995;92:6190-4.

72. Gordon S. Alternative activation of macrophages. Nat Rev Immunol. 2003:3:23-35.

73. Patel JR, Williams JL, Muccigrosso MM, Liu L, Sun T, Rubin JB, et al. Astrocyte TNFR2 is required for CXCL12-mediated regulation of oligodendrocyte progenitor proliferation and differentiation within the adult CNS. Acta Neuropathol. 2012;124:847-60.

74. Hauser SL, Doolittle TH, Lincoln R, Brown RH, Dinarello CA. Cytokine accumulations in CSF of multiple sclerosis patients: frequent detection of interleukin-1 and tumor necrosis factor but not interleukin-6. Neurology. 1990:40:1735-9.

75. Brogi A, Strazza M, Melli M, Costantino-Ceccarini E. Induction of intracellular ceramide by interleukin-1 beta in oligodendrocytes. J Cell Biochem. 1997;66:532-41.

76. Merrill JE. Effects of interleukin-1 and tumor necrosis factor-alpha on astrocytes, microglia, oligodendrocytes, and glial precursors in vitro. Dev Neurosci. 1991;13:130-7.

77. Schonberg DL, Popovich PG, McTigue DM. Oligodendrocyte generation is differentially influenced by toll-like receptor (TLR) 2 and TLR4-mediated intraspinal macrophage activation. J Neuropathol Exp Neurol. 2007;66:1124-35.

78. Suzumura A, Takeuchi H, Zhang G, Kuno R, Mizuno T. Roles of glia-derived cytokines on neuronal degeneration and regeneration. Ann N Y Acad Sci. 2006;1088:219-29.

79. Herx LM, Rivest S, Yong WW. Central nervous system-initiated inflammation and neurotrophism in trauma: IL-1 beta is required for the production of ciliary neurotrophic factor. J Immunol. 2000;165:2232-9.

80. Mason JL, Suzuki K, Chaplin DD, Matsushima GK. Interleukin-1 beta promotes repair of the CNS. J Neurosci. 2001:21:7046-52.

81. Arnett HA, Mason J, Marino M, Suzuki K, Matsushima GK, Ting JP. TNF alpha promotes proliferation of oligodendrocyte progenitors and remyelination. Nat Neurosci. 2001;4:1116-22.

82. Moyon S, Dubessy AL, Aigrot MS, Trotter M, Huang JK, Dauphinot L, et al. Demyelination causes adult CNS progenitors to revert to an immature state and express immune cues that support their migration. J Neurosci. 2015:35:4-20.

83. Mason JL, Ye P, Suzuki K, D'Ercole AJ, Matsushima GK. Insulin-like growth factor-1 inhibits mature oligodendrocyte apoptosis during primary demyelination. J Neurosci. 2000;20:5703-8.

84. Mason JL, Jones JJ, Taniike M, Morell P, Suzuki K, Matsushima GK. Mature oligodendrocyte apoptosis precedes IGF-1 production and oligodendrocyte progenitor accumulation and differentiation during demyelination/ remyelination. J Neurosci Res. 2000;61:251-62.

85. Mitchell K, Shah JP, Tsytsikova LV, Campbell AM, Affram K, Symes AJ. LPS antagonism of TGF-beta signaling results in prolonged survival and activation of rat primary microglia. J Neurochem. 2014;129:155-68.

86. Mosser DM, Edwards JP. Exploring the full spectrum of macrophage activation. Nat Rev Immunol. 2008:8:958-69.

87. Zhou X, Spittau B, Krieglstein K. TGFbeta signalling plays an important role in IL4-induced alternative activation of microglia. J Neuroinflammation. 2012;9:210.

88. Spittau B, Wullkopf L, Zhou X, Rilka J, Pfeifer D, Krieglstein K. Endogenous transforming growth factor-beta promotes quiescence of primary microglia in vitro. Glia. 2013;61:287-300. 
89. Zrzavy T, Hametner S, Wimmer I, Butovsky O, Weiner HL, Lassmann H. Loss of 'homeostatic' microglia and patterns of their activation in active multiple sclerosis. Brain. 2017;140:1900-13.

90. Esiri MM, Reading MC. Macrophage populations associated with multiple sclerosis plaques. Neuropathol Appl Neurobiol. 1987;13:451-65.

91. Ferguson B, Matyszak MK, Esiri MM, Perry VH. Axonal damage in acute multiple sclerosis lesions. Brain. 1997;120(Pt 3):393-9.

92. Prineas JW, Kwon EE, Cho ES, Sharer LR, Barnett MH, Oleszak EL, et al. Immunopathology of secondary-progressive multiple sclerosis. Ann Neurol. 2001;50:646-57.

93. Vogel DY, Vereyken EJ, Glim JE, Heijnen PD, Moeton M, van der Valk P, et al. Macrophages in inflammatory multiple sclerosis lesions have an intermediate activation status. J Neuroinflammation. 2013;10:35.

94. Dunn SE, Gunde E, Lee H. Sex-based differences in multiple sclerosis (MS): part II: rising incidence of multiple sclerosis in women and the vulnerability of men to progression of this disease. Curr Top Behav Neurosci. 2015;26:57-86.

95. Koch-Henriksen N, Sorensen PS. The changing demographic pattern of multiple sclerosis epidemiology. Lancet Neurol. 2010;9:520-32.

96. Ribbons KA, McElduff $P, B o z C$, Trojano M, Izquierdo G, Duquette $P$, et al. Male sex is independently associated with faster disability accumulation in relapse-onset MS but not in primary progressive MS. PLoS One. 2015:10:e0122686

97. Pelfrey CM, Cotleur AC, Lee JC, Rudick RA. Sex differences in cytokine responses to myelin peptides in multiple sclerosis. J Neuroimmunol. 2002;130:211-23.

98. Papenfuss TL, Rogers CJ, Gienapp I, Yurrita M, McClain M, Damico N, et al. Sex differences in experimental autoimmune encephalomyelitis in multiple murine strains. J Neuroimmunol. 2004;150:59-69.

99. Voskuhl RR, Pitchekian-Halabi H, MacKenzie-Graham A, McFarland HF, Raine CS. Gender differences in autoimmune demyelination in the mouse: implications for multiple sclerosis. Ann Neurol. 1996;39:724-33.

100. Cerghet M, Skoff RP, Bessert D, Zhang Z, Mullins C, Ghandour MS Proliferation and death of oligodendrocytes and myelin proteins are differentially regulated in male and female rodents. J Neurosci. 2006:26:1439-47.

101. Klein SL, Flanagan KL. Sex differences in immune responses. Nat Rev Immunol. 2016;16:626-38.

102. Swamydas M, Bessert D, Skoff R. Sexual dimorphism of oligodendrocytes is mediated by differential regulation of signaling pathways. J Neurosci Res. 2009;87:3306-19.

103. Rettew JA, Huet-Hudson YM, Marriott I. Testosterone reduces macrophage expression in the mouse of toll-like receptor 4, a trigger for inflammation and innate immunity. Biol Reprod. 2008;78:432-7.

\section{Publisher's Note}

Springer Nature remains neutral with regard to jurisdictional claims in published maps and institutional affiliations.

Ready to submit your research? Choose BMC and benefit from:

- fast, convenient online submission

- thorough peer review by experienced researchers in your field

- rapid publication on acceptance

- support for research data, including large and complex data types

- gold Open Access which fosters wider collaboration and increased citations

- maximum visibility for your research: over $100 \mathrm{M}$ website views per year

At $\mathrm{BMC}$, research is always in progress.

Learn more biomedcentral.com/submissions 